\title{
Low-molecular-mass labile metal pools in Escherichia coli: advances using chromatography and mass spectrometry
}

\author{
Hayley N. Brawley ${ }^{1}$ Paul A. Lindahl ${ }^{1,2}$ (D) \\ Received: 3 January 2021 / Accepted: 14 April 2021 / Published online: 8 May 2021 \\ (c) The Author(s) 2021
}

\begin{abstract}
Labile low-molecular-mass (LMM) transition metal complexes play essential roles in metal ion trafficking, regulation, and signalling in biological systems, yet their chemical identities remain largely unknown due to their rapid ligand-exchange rates and weak M-L bonds. Here, an Escherichia coli cytosol isolation procedure was developed that was devoid of detergents, strongly coordinating buffers, and EDTA. The interaction of the metal ions from these complexes with a SEC column was minimized by pre-loading the column with ${ }^{67} \mathrm{ZnSO}_{4}$ and then monitoring ${ }^{66} \mathrm{Zn}$ and other metals by inductively coupled plasma mass spectrometry (ICP-MS) when investigating cytosolic ultrafiltration flow-through-solutions (FTSs). Endogenous cytosolic salts suppressed ESI-MS signals, making the detection of metal complexes difficult. FTSs contained ca. $80 \mu \mathrm{M}$ $\mathrm{Fe}, 15 \mu \mathrm{M} \mathrm{Ni}, 13 \mu \mathrm{M} \mathrm{Zn}, 10 \mu \mathrm{M} \mathrm{Cu}$, and $1.4 \mu \mathrm{M} \mathrm{Mn}$ (after correcting for dilution during cytosol isolation). FTSs exhibited 2-5 Fe, at least $2 \mathrm{Ni}, 2-5 \mathrm{Zn}, 2-4 \mathrm{Cu}$, and at least $2 \mathrm{Mn}$ species with apparent masses between 300 and $5000 \mathrm{Da}$. Fe(ATP), $\mathrm{Fe}(\mathrm{GSH})$, and $\mathrm{Zn}(\mathrm{GSH})$ standards were passed through the column to assess their presence in FTS. Major LMM sulfur- and phosphorus-containing species were identified. These included reduced and oxidized glutathione, methionine, cysteine, orthophosphate, and common mono- and di-nucleotides such as ATP, ADP, AMP, and NADH. FTSs from cells grown in media supplemented with one of these metal salts exhibited increased peak intensity for the supplemented metal indicating that the size of the labile metal pools in $E$. coli is sensitive to the concentration of nutrient metals.
\end{abstract}

Keywords Labile metal pools $\cdot$ Electrospray ionization mass spectrometry $\cdot$ Cytosol $\cdot$ Size-exclusion chromatography Iron $\cdot$ Copper $\cdot$ Zinc $\cdot$ Manganese

\begin{tabular}{|c|c|}
\hline \multicolumn{2}{|c|}{ Abbreviations } \\
\hline AA & Ammonium acetate \\
\hline BPY & 2,2-Bipyridine \\
\hline $\mathrm{CV}$ & Column volume \\
\hline EDTA & Ethylenediaminetetraacetic acid \\
\hline EGTA & $\begin{array}{l}\text { Ethylene glycol-bis( } \beta \text {-aminoethyl ether)- } \\
N, N, N^{\prime}, N^{\prime} \text {-tetraacetic acid }\end{array}$ \\
\hline ESI-MS & Electrospray ionization mass spectrometry \\
\hline FTS & Flow-through solution \\
\hline GSH & Glutathione \\
\hline GSSG & Oxidized glutathione \\
\hline HPW & High-purity water \\
\hline \multicolumn{2}{|r|}{ Inductively coupled plasma mass spectrometry } \\
\hline \multicolumn{2}{|c|}{$\begin{array}{l}\triangle \text { Paul A. Lindahl } \\
\text { Lindahl@chem.tamu.edu }\end{array}$} \\
\hline \multicolumn{2}{|c|}{$\begin{array}{l}\text { Department of Chemistry, Texas A\&M University, } \\
\text { College Station, TX 77843-3255, USA }\end{array}$} \\
\hline $\begin{array}{l}2 \text { Depar } \\
\text { Univer }\end{array}$ & $\begin{array}{l}\text { ent of Biochemistry and Biophysics, Texas A\&M } \\
\text { ty, College Station, TX 77843, USA }\end{array}$ \\
\hline
\end{tabular}

$\begin{array}{ll}\text { LC } & \text { Liquid chromatography } \\ \text { LIP } & \text { Labile iron pool } \\ \text { LMM } & \text { Low-molecular-mass } \\ \text { phen } & 1,10 \text {-Phenanthroline } \\ \text { SEC } & \text { Size-exclusion chromatography } \\ \text { TPEN } & N, N, N^{\prime}, N^{\prime} \text {-Tetrakis(2-pyridinylmethyl)-1,2- } \\ & \text { ethanediamine }\end{array}$

\section{Introduction}

Transition metals have unique and exceptional catalytic properties which make them indispensable for life [1]. They are typically installed into the active sites of metalloenzymes where they orchestrate catalytic events, often involving substrate binding, electron transfer, and/or small-molecule activation. Ironically, the same properties that make them indispensable for life also make them dangerous. Many iron and copper complexes react with $\mathrm{O}_{2}$ or $\mathrm{H}_{2} \mathrm{O}_{2}$ (ala the Fenton reaction) to generate reactive oxygen species that damage 
DNA, membranes, proteins, and other essential cellular components $[2,3]$. The mismetallation of zinc and manganese into protein sites designed for other metals is also problematic $[4,5]$. For this reason, metal ion trafficking - the translocation of a metal from the plasma membrane where it enters the cell, to the site of installation into its "client" apoprotein, is not only critical for the cell's survival but must take place in a manner that protects the cell from the free metal and avoids toxic side reactions $[6,7]$. In many cases, metals are passed from one protein chaperone to the next [8], but in others, low-molecular-mass (LMM) metal complexes are likely involved [7]. Such labile metal complexes or pools also appear to be involved in metal ion homeostasis and signalling [9-13]. Metal-associated diseases often involve metal ion dysregulation, altered trafficking patterns, and/or increased oxidative damage [14, 15]. A more chemical-level understanding of labile metal trafficking would improve the understanding of such biological processes and lead to new strategies for treating metal-associated diseases.

Neither the exact chemical compositions of these trafficking metal complexes nor their cellular functions are established [7]. This knowledge gap is due, in large measure, to their lability-i.e. they possess ligands that exchange rapidly due to the inherent weakness of metal-ligand coordinate bonds. Ligand exchange rates can be slowed by increasing the denticity of the ligands, employing certain metal oxidation or spin states, or using particular donor atoms and coordination geometries. We hypothesize that the rate of lability has been adjusted, through evolutionary pressures, to be slow enough for such complexes to "hold together" during transit (to avoid arbitrary deleterious reactions) yet fast enough to release the metal efficiently to its client apoprotein. Such trafficking complexes are presumed to have nonproteinaceous ligands composed of metabolites possessing $\mathrm{O}, \mathrm{N}$, and/or $\mathrm{S}$ Lewis-basic donor atoms.

The most popular strategy for studying labile metal pools in cells is to expose intact cells to custom-designed fluorescence-based chelators [16-20]. These chelators enter cells and change their fluorescence properties upon binding labile metals. Quantifying these changes allows the size of labile metal pools to be quantified. This approach has the advantage of not disrupting intact cells. However, the chelator-based approach destroys the sought-after metal complexes, making it unlikely that this approach could ever be used to chemically identify metal trafficking complexes [2]. Moreover, chelators are not completely specific for a particular metal, much less for a particular metal complex, and different chelators and reaction conditions yield different estimates of the size and properties of labile metal pools [7].

We are developing a complementary approach to study labile metal complexes in which cells are disrupted and soluble lysates are passed through an ultrafiltration membrane [21-24]. The resulting flow-through-solution (FTS) is passed down a size-exclusion chromatography (SEC) column, and the eluate is sent to an online ICP-MS. The column employed here resolves species with molecular masses between ca. 100 and $7000 \mathrm{Da}$. One challenge of this LC-ICP-MS approach is that endogenous metal trafficking complexes might be altered during sample preparation or during migration through the column; the advantage is the potential for collecting and identifying endogenous metal trafficking complexes and ultimately for establishing cellular roles.

We have attempted to identify labile metal complexes in the cytosol of Escherichia coli but have encountered problems along the way. These include unwanted effects of a common chelator, unwanted secondary interactions of labile metals on the column, unwanted ligand-exchange reactions, and the unwanted suppression of ESI-MS signals due to salts present in the cytosol. Here, we describe our efforts to overcome these problems. Using the lessons learned, we then examined the labile metal content of the cytosol from $E$. coli and detected numerous LMM labile metal complexes. Although we have not established the chemical identity or cellular function of these complexes, we are closer to doing so than ever before.

\section{Experimental procedures}

\section{Strains and growth conditions}

A derivative of $E$. coli $\mathrm{K}-12$, MG1655, was transformed with bacteriophage-containing plasmid pZa31mycR [25]. MG1655-pZa31mycR cells were cultured in $50 \mathrm{~mL}$ of M9 minimal media containing $0.4 \%$ (w/v) glucose, $10 \mu \mathrm{M}$ natural-isotopic-abundance $\mathrm{Fe}^{\mathrm{III}}$ citrate, and $1 \mathrm{mM}$ chloramphenicol (Sigma-Aldrich) overnight at $37{ }^{\circ} \mathrm{C}$ with $200 \mathrm{rpm}$ shaking. These and all other concentrations given in the text are final concentrations after mixing. We determined by ICPMS that M9 media contained $0.9 \pm 0.6 \mu \mathrm{M} \mathrm{Fe}, 4 \pm 1 \mu \mathrm{M} \mathrm{Zn}$, $0.09 \pm 0.01 \mu \mathrm{M} \mathrm{Mn}$ and $1 \pm 1 \mu \mathrm{M} \mathrm{Cu}$. Once grown, cultures were transferred to $1.0 \mathrm{~L}$ of growth media. Ten independent $1.0 \mathrm{~L}$ batches of cells were grown and harvested at early $\left(\mathrm{OD}_{600} \sim 0.6\right)$, mid- $\left(\mathrm{OD}_{600} \sim 1\right)$, or late $\left(\mathrm{OD}_{600} \sim 2\right)$ exponential phase by centrifuging at $4000 \times g$ for $15 \mathrm{~min}$. Pellets (ca. $5 \mathrm{~g}$ wet cells) were washed in high-purity trace-metal-free double distilled-deionized water (HPW) and re-centrifuged at the same speed for $10 \mathrm{~min}$. Pellets were resuspended in $5.0 \mathrm{~mL}$ of $20 \mathrm{mM}$ ammonium bicarbonate (Sigma-Aldrich) buffered at $\mathrm{pH}$ 7.2. The suspension was transferred to a $15 \mathrm{~mL}$ polypropylene falcon tube, quickly frozen in liquid $\mathrm{N}_{2}$, and stored at $-20{ }^{\circ} \mathrm{C}$. Additional batches were grown in which the medium was supplemented with either $100 \mu \mathrm{M}$ of natural-isotopic-abundance $\mathrm{Fe}^{\mathrm{III}}$ citrate $(n=4), \mathrm{Zn}$ acetate 
$(n=3), \mathrm{MnCl}_{2}(n=1)$, or $1 \mu \mathrm{M} \mathrm{CuSO}_{4}(n=1)$; these cells were harvested in mid-exponential phase.

\section{Isolation of cytosol and FTS}

Frozen cells were thawed at $37^{\circ} \mathrm{C}$ with $100 \mathrm{rpm}$ shaking for $30 \mathrm{~min}$. The lysate was centrifuged at $10,000 \times g$ for $5 \mathrm{~min}$, transferred to a new $15 \mathrm{~mL}$ Falcon tube, and incubated with $20 \mu \mathrm{L}$ of $1.12 \mathrm{mg} / \mathrm{mL}$ DNase (Sigma-Aldrich) and $10 \mathrm{mM}$ $\mathrm{MgCl}_{2}$ (Acros Organics) for $30 \mathrm{~min}$ at $37^{\circ} \mathrm{C}$ with $100 \mathrm{rpm}$ shaking. Following DNA hydrolysis, the lysate was centrifuged at $100000 \times g$ for 60 min with a Beckman Coulter SW 32 Ti rotor in an Optima L-90K Ultracentrifuge. The resulting supernatant, defined as the cytosol, was brought into a chilled anaerobic glove box (MBraun Labmaster 120, 1-10 $\mathrm{ppm} \mathrm{O}_{2}, 4-8^{\circ} \mathrm{C}$ ) and passed through an Ultracel regenerated cellulose $3 \mathrm{kDa}$ ultrafiltration disc (EMD Millipore) using an Amicon filtration system; the solution that passed through the membrane was defined as flow-through-solution (FTS).

\section{Metal and ligand standards}

Stock solutions of $\mathrm{Fe}^{\mathrm{II}}$ sulfate (Fisher chemical), $\mathrm{Zn}$ acetate (Acros Organics), $\mathrm{MnCl}_{2}$ (Sigma-Aldrich), $\mathrm{CuSO}_{4}$ (Acros Organics), and $\mathrm{NiSO}_{4}$ (Sigma-Aldrich) $(1.0 \mathrm{mM}$ each) were prepared in HPW. Similar stock solutions of reduced glutathione, GSH, (Sigma-Aldrich), oxidized glutathione, GSSG, (Sigma-Aldrich), cysteine (Sigma-Aldrich), methionine (MP Biomedicals), $\mathrm{Na}_{2} \mathrm{HPO}_{4}$ (Sigma-Aldrich), $\mathrm{NaH}_{3} \mathrm{P}_{2} \mathrm{O}_{7}$ (Sigma-Aldrich), $\mathrm{Na}_{4} \mathrm{NADPH}$ (Sigma-Aldrich), $\mathrm{Na}_{2} \mathrm{NADH}$ (Sigma-Aldrich, $\mathrm{Na}_{2} \mathrm{AMP}$ (Sigma-Aldrich), NaADP (Sigma-Aldrich), $\mathrm{Na}_{2}$ ATP (Sigma-Aldrich) were prepared in HPW. Additional $10 \mathrm{mM}$ and $100 \mathrm{mM}$ stocks of GSH and ATP were prepared in HPW. All stocks were stored at $4{ }^{\circ} \mathrm{C}$. For LC-ICP-MS analysis, stock standards were diluted (day-of) to the desired final concentration in mobile phase (see LC-ICP-MS and elemental analysis). $\mathrm{Na}$ (polyphosphate) (Sigma-Aldrich) was prepared at $1.1 \mathrm{~g} /$ $\mathrm{mL}$ and filtered through the $3 \mathrm{kDa}$ membrane; the filtrate was diluted in mobile phase prior to LC-ICP-MS analysis.

\section{LC-ICP-MS and elemental analysis}

Primary LC-ICP-MS analyses were performed on a single Superdex ${ }^{\text {TM }}$ Peptide 10/300 GL (GE Life Sciences) SEC column. Additional analyses were performed on two such columns linked in series. The mobile phase passed through the column at $0.6 \mathrm{~mL} / \mathrm{min}$ for the single and $0.25 \mathrm{~mL} / \mathrm{min}$ for the double column using an Agilent 1260 bio-inert quaternary pump (G5611A) with diode array (G4212B), fraction collector (G5664A), and multisampler (G5688A). The entire LC system was located inside the glove box. Eluate flowed to an ICP-MS (Agilent 7700x) located outside of the box where ${ }^{23} \mathrm{Na},{ }^{39} \mathrm{~K},{ }^{31} \mathrm{P},{ }^{34} \mathrm{~S},{ }^{55} \mathrm{Mn},{ }^{56} \mathrm{Fe},{ }^{57} \mathrm{Fe},{ }^{60} \mathrm{Ni},{ }^{63} \mathrm{Cu},{ }^{65} \mathrm{Cu}$, ${ }^{66} \mathrm{Zn},{ }^{67} \mathrm{Zn}$, and ${ }^{68} \mathrm{Zn}$ were detected. The mobile phase was either $20 \mathrm{mM}$ or $50 \mathrm{mM}$ ammonium acetate (AA) pH 6.5 for LC-MS (Sigma-Aldrich), which had previously passed through a $0.22 \mu \mathrm{m}$ filter using a Stericup vacuum filtration system (Corning) and then degassed using a Schlenk line prior to import into the box. AA was selected as the mobile phase buffer due to its volatility and compatibility with both ICP-MS and ESI-MS. Samples $(150 \mu \mathrm{L})$ were injected automatically using the multisampler. Peak elution volumes $\left(V_{e}\right)$ were calibrated to molecular masses using standards listed in Table S1. Designated peaks were simulated with Fityk software (fityk.nieto.pl) employing the Levenberg-Marquardt algorithm with a built-in Gaussian function.

For elemental analysis of samples, three aliquots (50-100 $\mu \mathrm{L}$ ) of lysate, cytosol, and FTS from the ten independent batches were transferred into $15 \mathrm{~mL}$ polypropylene falcon tubes. $150 \mu \mathrm{L}$ of trace-metal-grade $70 \%(w / v)$ nitric acid (Thermo Fisher Scientific) was added to each tube. Tubes were capped, sealed with electrical tape, vortexed, and incubated at $70{ }^{\circ} \mathrm{C}$ for $\sim 15 \mathrm{~h}$. Samples were cooled to RT and then diluted to a final volume of $3 \mathrm{~mL}$ with HPW followed by ICP-MS analysis.

\section{${ }^{67} \mathrm{Zn}$ loading of SEC column}

Prior to loading, the column was cleaned by passing 500 $\mu \mathrm{L}$ of a chelator cocktail through it. The cocktail included $50 \mu \mathrm{M}$ each of ethylenediaminetetraacetic acid (EDTA) (Sigma-Aldrich), ethylene glycol-bis( $\beta$-aminoethyl ether)$N, N, N^{\prime}, N^{\prime}$-tetraacetic acid (EGTA) (Sigma-Aldrich), 1,10-phenanthroline (phen) (Acros Organics), 2,2-bipyridine (BPY) (Alfa Aesar), bathocuproinedisulfonic acid (SigmaAldrich), deferoxamine (END Millipore), $\left(N, N, N^{\prime}, N^{\prime}\right.$ tetrakis(2-pyridinylmethyl)-1,2-ethanediamine (TPEN) (Sigma-Aldrich), and $1 \mathrm{mM}$ ascorbic acid (Acros Organics). Three separate aliquots of the cocktail were injected onto the column with alternating injections of $500 \mu \mathrm{L}$ HPW. A column volume $(\mathrm{CV}=24 \mathrm{~mL})$ of the mobile phase $50 \mathrm{mM}$ AA (Sigma-Aldrich), pH 6.5, was passed between injections.

Three methods were used to load the column. In the first method, > $10 \mathrm{CVs}$ of $10 \mu \mathrm{M}^{67} \mathrm{ZnSO}_{4}$ (90\%; Isoflex USA) in HPW was passed as the mobile phase through the column, and then the mobile phase was changed to $50 \mathrm{mM} \mathrm{AA}, \mathrm{pH}$ 6.5 , to rinse-off unbound ${ }^{67} \mathrm{Zn}$. This method eventually contaminated the LC system with ${ }^{67} \mathrm{Zn}$, which was painstakingly removed by excessive flushing with dilute $\mathrm{HCl}, \mathrm{pH} 3$. In the second method, $500 \mu \mathrm{L}$ of $10 \mu \mathrm{M}^{67} \mathrm{ZnSO}_{4}$ was injected onto the column. After passing $1 \mathrm{CV}$ of $50 \mathrm{mM} \mathrm{AA}, \mathrm{pH} 6.5$, mobile phase, $500 \mu \mathrm{L}$ of HPW was injected, followed by another $\mathrm{CV}$ of mobile phase. These injections were repeated $4 \times$ more. The column was then rinsed with $50 \mathrm{mM}$ AA, $\mathrm{pH}$ 
6.5, until a flat baseline for ${ }^{66} \mathrm{Zn}$ was attained. In the third method (currently used), $5 \mathrm{CVs}$ of a mobile phase consisting of $5 \mu \mathrm{M}^{67} \mathrm{ZnSO}_{4}$ in $50 \mathrm{mM} \mathrm{AA}, \mathrm{pH} 6.5$, were passed through the column, followed by $50 \mathrm{mM} \mathrm{AA}, \mathrm{pH} 6.5$, until a flat ${ }^{66} \mathrm{Zn}$ baseline was achieved. Due to heavy use, the loading procedure was repeated bimonthly.

\section{ESI-MS analysis}

Electrospray ionization mass spectrometry (ESI-MS) was performed using a Thermo Scientific Q Exactive Focus (Waltham, Massachusetts) instrument. FTSs, LC fractions, and standards (GSH, ATP, etc.) were diluted $2 \times$ or $20 \times(5$ $\mu \mathrm{L}$ sample $+5 \mu \mathrm{L} \mathrm{CH}_{3} \mathrm{OH}$ for $2 \times ; 10 \mu \mathrm{L}$ sample $+200 \mu \mathrm{L}$ $\mathrm{CH}_{3} \mathrm{OH}$ for $20 \times$ using LC-MS-grade methanol (Thermo Fisher Scientific)), depending on metal and salt concentrations in the sample. Samples were injected into a $10 \mu \mathrm{L}$ loop, using methanol as a mobile phase at a flow rate of $300 \mu \mathrm{L} /$ min. The Q Exactive Focus HESI source was operated in full MS $(66-1000 \mathrm{~m} / \mathrm{z})$ in positive and negative modes. The mass resolution was tuned to 70,000 FWHM at $\mathrm{m} / \mathrm{z} 200$. Spray voltage was $3.5 \mathrm{kV}$ for positive mode and $3.3 \mathrm{kV}$ for negative mode. Sheath gas and auxiliary gas flow rates were 7 and 0 AU, respectively. Transfer capillary temperature was held at $270{ }^{\circ} \mathrm{C}$ and the S-Lens RF level was $50 \mathrm{~V}$. Exactive Series 2.11/Xcalibur 4.2 software was used for data acquisition and processing. Mass accuracy was within $\pm 2 \mathrm{ppm}$.

\section{Results}

Our long-term objective is to determine the chemical composition of the LMM labile metal pools in E. coli and other biological systems. We previously detected LMM metal complexes in E. coli and Saccharomyces cerevisiae [21-24] but did not identify them; the main objective of those studies was to establish reproducibility. We initially focussed on zinc because of its redox inactivity and ability to form stable coordination complexes, properties that increased our likelihood of success. We selected the Gram-negative model bacterium E. coli because much supporting mechanistic information was known about metal ion metabolism in this organism. FTS, which should exclusively contain species with masses $<3 \mathrm{kDa}$, was subjected to SEC. Eluates were sent directly to an ICP-MS for the detection of metals, sulfur, and phosphorus. The LC was located in a refrigerated inert atmosphere glove box to avoid oxidation of metal ions and sulfhydryl groups and to minimize ligand-exchange reactions.

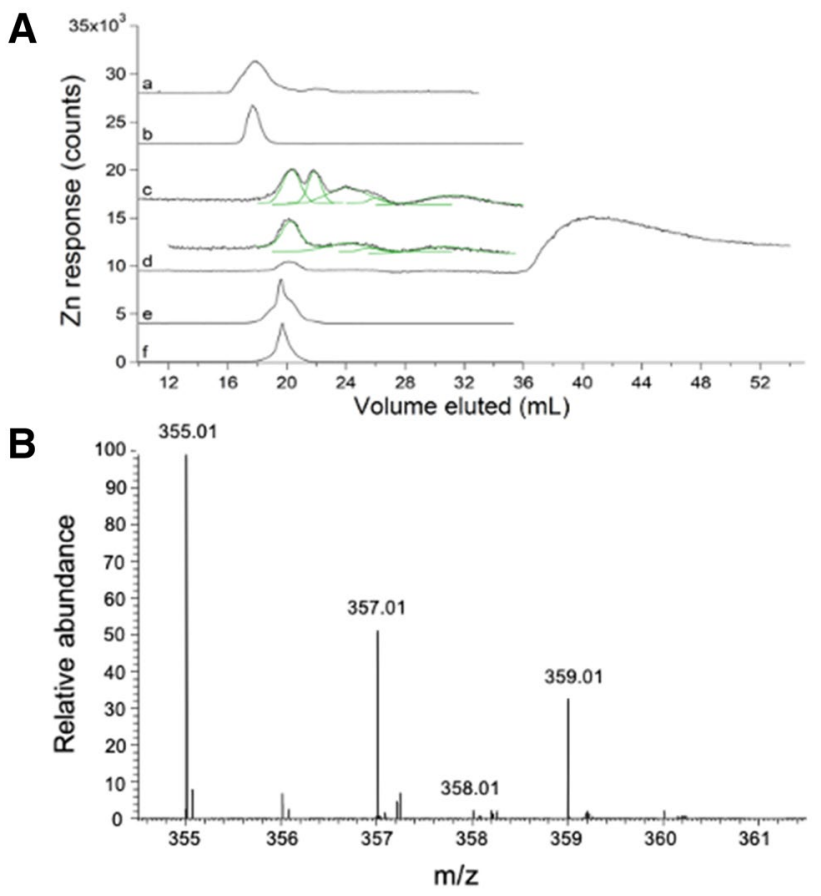

Fig. 1 Zn-detected LC-ICP-MS chromatograms (A) and ESI-MS spectrum (B) of E. coli FTS: A: (a) average of 3 traces of cytosolic FTS isolated from MG1655 E. coli cells using EDTA [21]. (b) $1 \mu \mathrm{M} \mathrm{ZnCl}_{2}+1 \mu \mathrm{M}$ EDTA $\div 4$. The mobile phase for (a) and (b) was $20 \mathrm{mM}$ ammonium bicarbonate $\mathrm{pH}$ 8.5. (c) average of 8 independent traces of FTS from RYMG1655+pZa31mycR E. coli cytosol (black) overlaid with simulations (green). Unless specified otherwise, no EDTA was used during isolation, the default mobile phase was $50 \mathrm{mM}$ AA pH 6.5, and the cells were MG1655+pZa31mycR. (d) Average of 2 traces from independent FTSs of cells grown in $100 \mu \mathrm{M}$ $\mathrm{Zn}$ supplemented growth medium. Offset is $(\mathrm{d}) \times 5$. (e), FTS as in (c) but incubated with $500 \mu \mathrm{M}$ EDTA $\div 20$. (f), $1 \mu \mathrm{M} \mathrm{Zn}$ acetate $+20 \mu \mathrm{M}$ EDTA $\div 10$. B: Positive mode spectra of $\mathrm{Zn}$-containing LC fractions from FTSs isolated as in (a), then lyophilized and resuspended in $\mathrm{D}_{2} \mathrm{O}$. Lines with indicated masses reflect the $1+$ charge state of $\mathrm{Zn}$ (EDTA) and showed the expected isotope pattern. $\times \#$ and $\div \#$ refer to an \#-fold multiplication/division of the detector response in the plotted trace

\section{A holin/endolysin-containing strain allowed cell lysis without EDTA}

We became acutely concerned with the chelator EDTA in our buffers when we noticed that the LMM Zn species previously detected in FTSs (Fig. 1A, trace a) co-migrated with Zn(EDTA) (Fig. 1A, trace b). To investigate further, we lyophilized the $\mathrm{Zn}$-containing fractions that eluted from the column and rehydrated the dried material in minimal $\mathrm{D}_{2} \mathrm{O}$. ESI-MS of the resulting solution (Fig. 1B) demonstrated the presence of $\mathrm{Zn}$ (EDTA), including the pattern expected from the natural isotope distribution (49\% ${ }^{64} \mathrm{Zn} ; 28 \%{ }^{66} \mathrm{Zn} ; 4 \%{ }^{67} \mathrm{Zn} ; 18 \%{ }^{68} \mathrm{Zn}$ ). We removed EDTA from all buffers but discovered that removing it from the lysis buffer decreased the effectiveness of cell lysis. We 
switched to a custom strain of $E$. coli $(\mathrm{MG} 1655+\mathrm{pZa}$ $31 \mathrm{mycR}$ ) in which lysis occurred via canonical phage lysis. The strain contained a plasmid encoding two phage proteins, holin and endolysin, which upon freezing and thawing initiated cell lysis. This strain was used for the remainder of the study.

\section{EDTA-free cytosolic FTS contained 2-5 labile LMM zinc species with a collective concentration of $\sim 13 \mu \mathrm{M}$}

We isolated cytosolic FTSs from ten independent batches of $E$. coli cells in the absence of EDTA and passed them through a ${ }^{67} \mathrm{Zn}$-loaded column (see below). The cells contained an average of $400 \pm 200 \mu \mathrm{M} \mathrm{Zn}$, whereas isolated cytosol contained $200 \pm 100 \mu \mathrm{M} \mathrm{Zn}$, and FTS contained $13 \pm 3 \mu \mathrm{M} \mathrm{Zn}$ (determinations were back-calculated to concentrations within the cell). EDTA-free FTS displayed a different chromatogram that included, on average, 5 partially resolved LMM Zn peaks (Fig. 1A, trace c). The green lines simulating these peaks used parameters given in Table S2. A few individual traces exhibited just 2 of those Zn peaks (Fig. S1). We considered that the growth phase at harvest (early, mid, or late exponential) might reveal significant differences, but none were evident and so traces were averaged. Traces were obtained using $50 \mathrm{mM}$ AA, $\mathrm{pH}$ 6.5, the default mobile phase for the entire study. When EDTA-free FTS was treated with EDTA, the major peak in the resulting trace (Fig. 1A, trace e) migrated with Zn(EDTA) (Fig. 1A, trace f). Clearly, Zn peaks obtained in the absence of EDTA more accurately represented the labile zinc pool in E. coli. Under these growth conditions, this pool constituted about $3 \%$ of the total zinc in the cell. We concluded that the detected $\mathrm{Zn}$ species were labile towards EDTA, and that the LMM Zn complex previously reported [21] was probably Zn(EDTA). All other FTSs described in this manuscript were isolated in the absence of EDTA.

Supplementing the growth medium with $100 \mu \mathrm{M} Z \mathrm{Zn}$ acetate led to large increases in the LMM $\mathrm{Zn}$ pool, to an average of $200 \pm 100 \mu \mathrm{M}$ (range from 70 to $320 \mu \mathrm{M}$ ). Most of the additional $\mathrm{Zn}$ eluted as an intense broad peak at ca. $40 \mathrm{~mL}$ (Fig. 1A, trace d) which likely arose from hydrated $\mathrm{Zn}$ ions that interacted strongly with the column. Such peaks were only observed when the growth medium was supplemented with Zn acetate. Curiously, the Zn peak with $V_{e} \approx$ $21 \mathrm{~mL}$ in traces from un-supplemented FTS was absent in supplemented FTS whereas the other 4 peaks were present under both conditions, and with similar relative intensities. See Table S2 for parameters used to simulate these and other peaks.

\section{Zinc loading minimized metal interaction with columns}

We previously reported that labile LMM metal complexes partially adsorbed onto, and desorbed from, the SEC column $[22,23]$. Metal ions likely participated in secondary ionic interactions with basic groups on the solid support such as carboxylates [26]. Previously, we cleaned the column regularly and extensively using a chelator cocktail, and on occasion, with dilute acid and base. However, low detector response and spurious metal peaks remained problematic. The latter effect was due to "injection-initiated" metal ion desorption in which simply injecting a sample perturbed the column sufficiently to dislodge small quantities of metal ions.

We developed three methods to minimize adsorption/desorption problems further, all of which involved saturating basic sites on the column with a particular isotope of zinc $\left({ }^{67} \mathrm{Zn}\right)$ and then detecting two different isotopes $\left({ }^{66} \mathrm{Zn}\right.$ and ${ }^{68} \mathrm{Zn}$ ) in subsequent analyses of samples containing natural-abundance isotopes of zinc. Zinc loading by Method 2 (see "Experimental procedures") caused $\sim 0.1 \%$ of the sites on the solid support to coordinate ${ }^{67} \mathrm{Zn}$ ions. Loading by Method 3 caused binding of $2.5 \%$ of sites. Although fewer sites were bound by Method 2, blocking them was enough to minimize the interaction of hydrated metal ions with the column. We suspect that the affinity of the sites to $\mathrm{Zn}$ was variable and that the strongest binders caused most of the problem. Method 3 provided the best reproducibility and largely eliminated spurious LC peaks. Regardless of the method, loaded ${ }^{67} \mathrm{Zn}$ ions gradually desorbed, such that the column had to be reloaded periodically.

The behavior of $\mathrm{Zn}$ loading is illustrated in Fig. 2 . The grey ${ }^{66} \mathrm{Zn}$-detected traces in Fig. $2 \mathrm{~A}$, traces a-c were obtained by passing 5,2 , and $1 \mu \mathrm{M}$ natural-abundance $\mathrm{Zn}$ acetate through an unloaded column. Peaks were extremely broad and showed severe tailing. Distorted peak shapes likely reflected binding interactions with the column that were strong enough to hinder passage but weak enough to allow passage within the timeframe of the experiment. As the concentration of $\mathrm{Zn}$ increased $(\mathrm{c} \rightarrow \mathrm{a})$, the elution volume $\left(V_{e}\right)$, tailing, and peak-width all decreased. We concluded that as the concentration of $\mathrm{Zn}$ in the sample increased, column interactions declined, requiring less elution volume and affording greater homogeneity. The same phenomenon was evident in the corresponding black ${ }^{66} \mathrm{Zn}$ traces of Fig. 2A, which were obtained by passing the same solutions through $a{ }^{67} \mathrm{Zn}$-loaded column. Elution volumes were reduced further when the loaded column was used, and linewidths were narrowed, indicating diminished column interactions. We used a "ghost column" (consisting of PEEK tubing that replaced the actual column) and peak-fitting software to show that $>90 \%$ 
Fig. 2 Chromatograms of aqueous zinc (A), iron (B), manganese (C), nickel (D), and copper (E) on an unloaded (grey) and ${ }^{67} \mathrm{ZnSO}_{4}$-loaded single SEC column (black). A (a-c), 5, 2, and $1 \mu \mathrm{M} \mathrm{Zn}$ acetate, respectively. B (a-c), 5, 2, and $1 \mu \mathrm{M} \mathrm{FeSO}_{4} \cdot \mathbf{C ~}(\mathrm{a}-\mathrm{c}), 5,2$, and $1 \mu \mathrm{M}$ $\mathrm{MnCl}_{2}$. D (a-c), 5, 2, and $1 \mu \mathrm{M} \mathrm{NiSO}_{4}$. E (a-b), 5 and $1 \mu \mathrm{M} \mathrm{CuSO}_{4}$

of injected $\mathrm{Zn}$ in samples eventually eluted from both loaded and unloaded columns.

A similar though less severe phenomenon was evident by passing aqueous iron, nickel, and manganese ions through the column. The grey traces in Fig. 2B, obtained by passing 5, 2, and $1 \mu \mathrm{M} \mathrm{FeSO}_{4}$ through the column, exhibited broad peaks with some tailing. As the concentration of iron increased $(\mathrm{c} \rightarrow \mathrm{a}), V_{e}$, linewidths, and tailing all decreased. The corresponding black traces, obtained by injecting the sample solutions onto a loaded column, exhibited sharper peaks and lower $V_{e}$. Again, this illustrated a decline in column interactions due to ${ }^{67} \mathrm{Zn}$ loading. Nearly $100 \%$ of the injected iron eventually eluted from the column regardless of whether it was loaded. Two effects might have been involved, including an interaction with the column that delayed elution and caused tailing, and an "overloading" effect in which disproportionately more metal ions bound to the column when higher concentrations were injected, thereby causing injector-initiated spurious metal peaks. The same trend was observed when passing 5,2, and $1 \mu \mathrm{M}$ $\mathrm{NiSO}_{4}$ through the columns (Fig. 2D). Passing manganese ions through the column afforded sharp and nearly Gaussian peaks (Fig. 2C) regardless of whether the column was loaded. Of the metals tested, manganese ions probably interacted least with the column.

The opposite situation was found with aqueous copper ions, as little of the injected copper eluted from the column (Fig. 2E). More copper eluted from the ${ }^{67} \mathrm{Zn}$-loaded column than from an unloaded column, but peak shapes were similar. Only $1 \%$ of the copper injected onto the $\mathrm{Zn}$ loaded column eluted; the rest must have been adsorbed, accounting for the poor signal-to-noise ratio. The observed signal is likely due to contamination in the mobile phase. We suspect that aqueous copper ions bound the column so strongly that they displaced bound ${ }^{67} \mathrm{Zn}$ ions; however, we were unable to detect copper-dependent ${ }^{67} \mathrm{Zn}$ elution. The different behaviors observed followed the Irving-Williams series [27] in which the order of binding strengths (to classical O-, N-, and S-based ligands) varied in the order (weakest) $\mathrm{Mn}^{\mathrm{II}}<\mathrm{Fe}^{\mathrm{II}}<\mathrm{Ni}^{\mathrm{II}}<\mathrm{Zn}^{\mathrm{II}}<\mathrm{Cu}^{\mathrm{II}}$ (strongest).
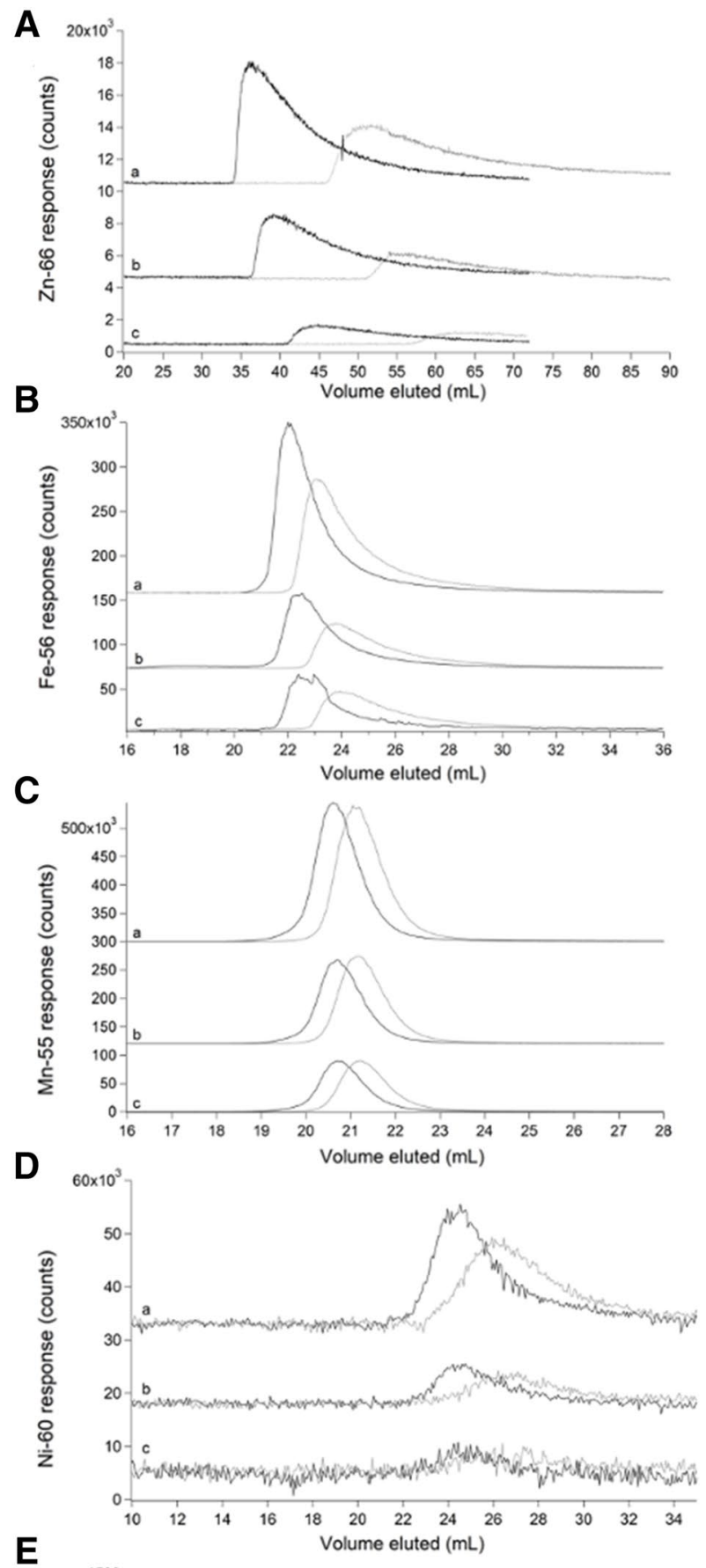

E

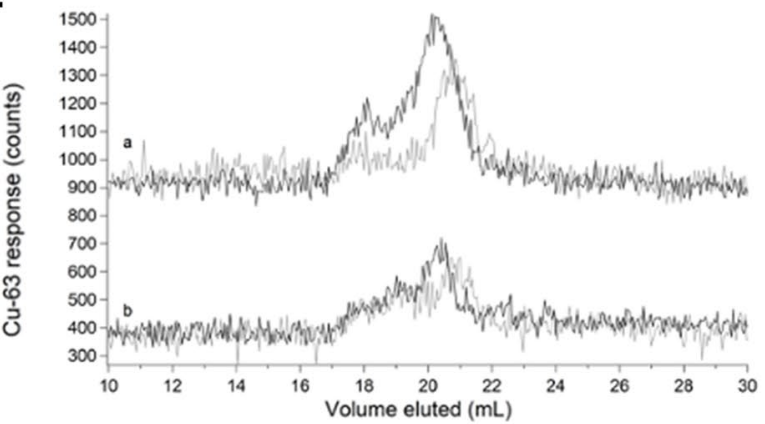




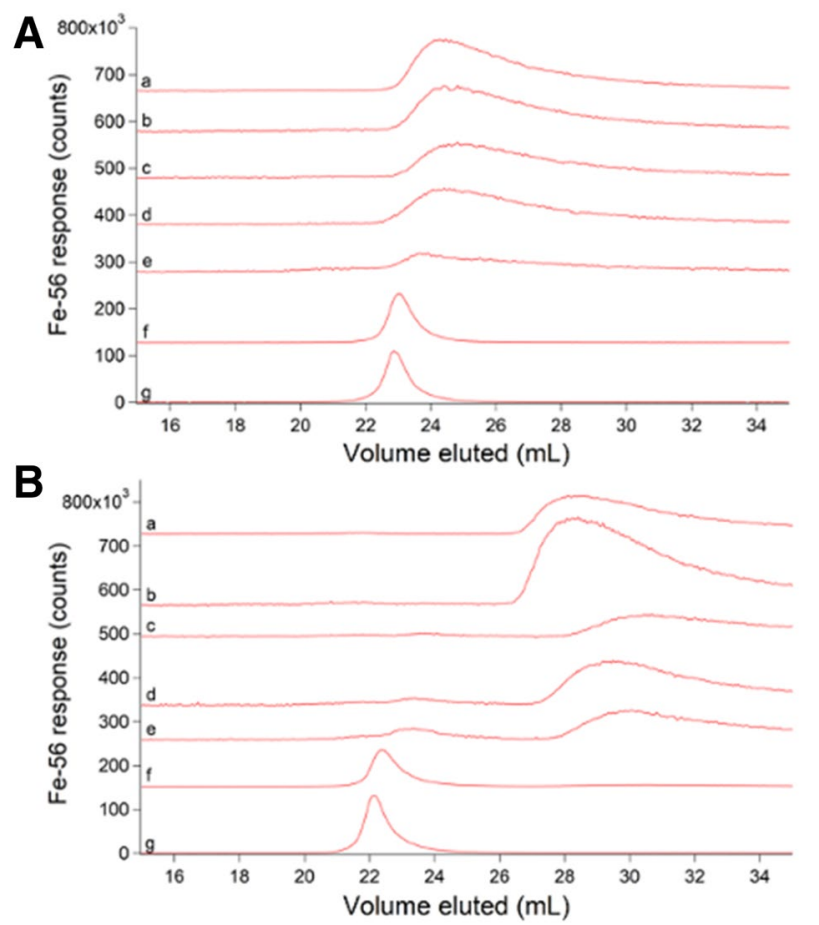

Fig. 3 Iron-detected chromatograms of Fe(ATP) using $50 \mathrm{mM}$ (A) and $20 \mathrm{mM}(\mathbf{B})$ ammonium acetate $\mathrm{pH} 6.5$ mobile phases. All traces were from samples containing $1 \mu \mathrm{M} \mathrm{FeSO}_{4}+$ the following (final) $\mu \mathrm{M}$ concentrations of $\mathrm{Na}_{2} \mathrm{ATP}$. A: (a) 0; (b) 5; (c) 10; (d) 25; (e) 50; (f) 500; (g) 1000. B: (a) 0; (b) 5; (c)10; (d) 25; (e) 50; (f) 500; (g) 1000

\section{Chromatographic behavior of iron and zinc standards reflected the $M-L$ binding strength of the complex}

At this point, we shifted focus to iron, as its interaction with the ${ }^{67} \mathrm{Zn}$-loaded column was weaker than zinc's, yielding sharper peaks that were easier to study. Iron(ATP) is a candidate cytosol trafficking complex [28], and so we examined its chromatographic properties by mixing $1 \mu \mathrm{M}$ $\mathrm{FeSO}_{4}$ with increasing concentrations of ATP. Both iron and phosphorus signals were monitored. In the absence of ATP, iron migrated as a broad tailing peak with $V_{e} \approx 24 \mathrm{~mL}$ (Fig. 3A, trace a). As ATP concentrations increased (and with $\left[\mathrm{FeSO}_{4}\right]$ fixed at $1 \mu \mathrm{M}$ ), the iron peak shifted left and sharpened, ultimately eluting at ca. $23 \mathrm{~mL}$. This behavior indicated that iron and ATP formed a complex at sufficiently high concentrations of ATP but that the complex dissociated as it migrated through the column such that the iron eluted at different mobile phase volumes depending on the ATP concentration. The chromatographic behavior of ATP was independent of iron but was unexpectedly complicated nevertheless (Fig. S2, panel A). ATP migrated as 3 peaks, including a major peak at $23.5 \mathrm{~mL}$ and two low-intensity "satellites" at $22 \mathrm{~mL}$ and $25.5 \mathrm{~mL}$. The satellite peaks did not comigrate with inorganic phosphate or ADP, which

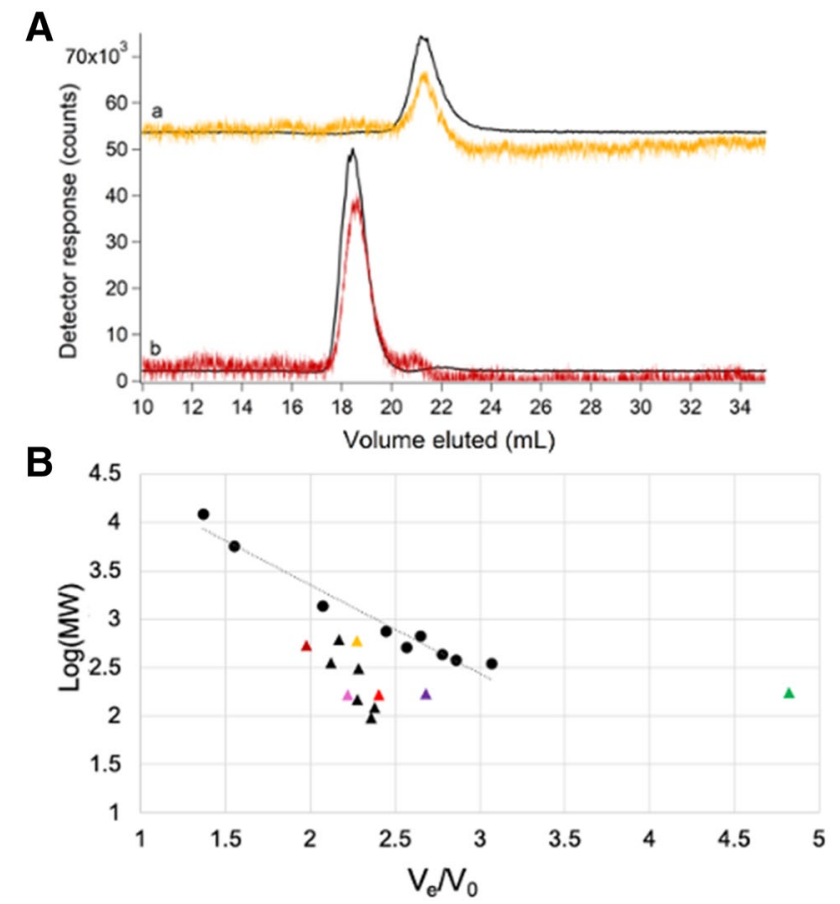

Fig. 4 Chromatograms of $\left[\mathrm{Fe}(\text { phen })_{3}\right]^{2+}$ (orange) and $\left[\mathrm{Fe}(\mathrm{BPY})_{3}\right]^{2+}$ (red) (a) and deviations from expected molecular mass trend line (B). A: (a) $2 \mu \mathrm{M} \mathrm{FeSO}_{4}+20 \mu \mathrm{M}$ phen detected by iron ICP-MS (black, $\div 1.33$ ) and at $510 \mathrm{~nm}$ (orange, $\times 10^{4}$ ); (b) $2 \mu \mathrm{M}$ $\mathrm{FeSO}_{4}+20 \mu \mathrm{M}$ BPY detected by iron ICP-MS (black, $\div 2$ ) and at $523 \mathrm{~nm}\left(\mathrm{red}, \times 10^{4}\right)$. B: Molecular mass calibration curve and trendline $\left(\log (\mathrm{MM})=-0.9204\left(V_{\mathrm{e}} / V_{0}\right)+5.1971 ; R^{2}=0.9575\right)$ using standards from Table S1 (circles) and a Zn-loaded single column. Deviant standards are shown as triangles. $\left[\mathrm{Fe}(\text { phen })_{3}\right]^{2+}$ and $\left[\mathrm{Fe}(\mathrm{BPY})_{3}\right]^{2+}$ are color-coordinated to UV-Vis traces in $\mathbf{A}$. Aqueous metal standards were $\mathrm{Zn}$ acetate (green), $\mathrm{FeSO}_{4}$ (bright red), $\mathrm{MnCl}_{2}$ (pink) and $\mathrm{NiSO}_{4}$ (purple)

would have indicated hydrolysis of the standard. They may have been due to impurities in the ATP standard.

The chromatographic behavior of Fe(ATP) changed when the concentration of AA in the mobile phase was lowered from 50 to $20 \mathrm{mM}$. Using $20 \mathrm{mM}$ AA, the $1 \mu \mathrm{M} \mathrm{FeSO}_{4}$ sample lacking ATP eluted as a broad trailing iron peak at ca. $27 \mathrm{~mL}$ (Fig. 3B, trace a), a downstream shift of ca. $2 \mathrm{~mL}$ relative to the peak obtaining using $50 \mathrm{mM} \mathrm{AA}$. We interpreted this as indicating a stronger interaction between aqueous iron and the column. As the ATP concentration increased, the broad tailing peak remained until the ATP concentration was $\geq 500 \mu \mathrm{M}$. At such high ATP concentrations, the broad tailing peak was replaced by a sharper peak with a more Gaussian lineshape ca. $23 \mathrm{~mL}$ (Fig. 3B, traces f, g). This peak shifted and sharpened with increasing ATP concentration. We concluded that an Fe(ATP) complex formed more tightly when $20 \mathrm{mM}$ AA was used in the mobile phase but that the interaction between iron and the column was also stronger, giving rise to the broad tailing and lack of comigrating $\mathrm{Fe}$ and $\mathrm{P}$ signals. The corresponding phosphorus 
traces using $20 \mathrm{mM}$ AA followed the same general trend as with $50 \mathrm{mM} \mathrm{AA}$, including the two satellite peaks (Fig. S2, panel B).

Traces of two tight-binding iron complexes, $\left[\mathrm{Fe}(\mathrm{phen})_{3}\right]^{2+}$ and $\left[\mathrm{Fe}(\mathrm{BPY})_{3}\right]^{2+}$, where phen $=1,10$-phenanthroline and $\mathrm{BPY}=2,2^{\prime}$-bipyridine, were simpler to interpret. Reported $\log \beta$ values for these complexes are 21.2 and 17.5 , respectively [29]. Our LC-ICP-MS system included an online diode-array UV-Vis spectrometer. This allowed the intact colored complexes and the metal to be monitored simultaneously and independently as they eluted from the column. Both iron and UV-Vis traces of $\left[\mathrm{Fe}(\text { phen })_{3}\right]^{2+}$ and $\left[\mathrm{Fe}(\mathrm{BPY})_{3}\right]^{2+}$ exhibited single comigrating peaks (Fig. 4A, traces $\mathrm{a}, \mathrm{b})$, establishing that these complexes remained intact as they migrated through the column.

The column was calibrated by plotting the logarithm of the standard molecular mass $v s$. the ratio of $V_{e}$ to void volume $\left(V_{\mathrm{e}} / V_{0}\right)$ where $V_{0}$ was determined to be $9.3 \mathrm{~mL}$ using thyroglobulin. We expected that species would migrate through the column with $V_{e}$ inversely proportional to the logarithm of molecular mass of the species, but this was not always the case (Fig. 4B, triangles). For example, $\left[\mathrm{Fe}(\text { phen })_{3}\right]^{2+}$ has a higher molecular mass than $\left[\mathrm{Fe}(\mathrm{BPY})_{3}\right]^{2+}(570$ vs. $524 \mathrm{Da})$, but it migrated as though it had a lower mass (Fig. 4B, yellow vs. dark red triangle). This problem was exacerbated for weakly coordinated metal complexes in which $V_{e}$ shifted with changes in the concentration of the ligand, mobile phase, and the extent of interaction with the column.

Fig. 5 Chromatograms of $\mathrm{FeSO}_{4}$ (red) and GSH (yellow) using $50 \mathrm{mM}(\mathbf{A})$ and $20 \mathrm{mM}$ (B) AA mobile phase buffers. A: (a) $1 \mu \mathrm{M} \mathrm{FeSO}_{4}+100 \mu \mathrm{M}$ GSH $\times 5$; (b) same as (a) but with $1 \mathrm{mM} \mathrm{GSH}$; (c) same as (a) but with $100 \mathrm{mM} \mathrm{GSH} \div 10$. B: (a) $1 \mu \mathrm{M} \mathrm{FeSO}_{4}+100 \mu \mathrm{M}$ $\mathrm{GSH} \times 5$; (b) same as (a) but with $1 \mathrm{mM} \mathrm{GSH} \div 10$; (c) same as (a) but with $50 \mathrm{mM}$ $\mathrm{GSH} \div 10$. Dashed lines are simulations
$\mathrm{Fe}(\mathrm{GSH})$ is another candidate cytosol trafficking complex $[30,31]$, and so we examined the chromatographic properties of $1 \mu \mathrm{M} \mathrm{FeSO}_{4}$ solutions mixed with increasing concentrations of GSH in hopes of generating the complex. Each solution was passed down the column (using $50 \mathrm{mM}$ AA mobile phase), and the eluate was monitored for iron and sulfur (Fig. 5A). The experiment was repeated using $20 \mathrm{mM}$ AA mobile phase (Fig. 5B). GSH migrated with $V_{e} \approx 21 \mathrm{~mL}$ regardless of mobile phase whereas $V_{e}$ for the iron peaks shifted depending on the GSH concentration and mobile phase. At low GSH concentrations, iron migrated as a broad tailing peak at $V_{e} \approx 23 \mathrm{~mL}$ (Fig. 5A, trace a) and $29 \mathrm{~mL}$ (Fig. 5B, trace a), depending on mobile phase. These peaks were nearly identical to those observed with $\mathrm{FeSO}_{4}$ alone. In solutions containing intermediate concentrations of GSH, the iron peak shifted left and sharpened (Fig. 5A, trace $\mathrm{b}$ and $5 \mathrm{~B}$, trace $\mathrm{b}$ ). The traces of solutions containing 50 or $100 \mathrm{mM} \mathrm{GSH}$ had a broad peak that migrated at about the same $V_{e}$ as peaks present in solutions containing 0.1 and $1 \mathrm{mM}$ GSH (red dashed lines). In addition, the traces involving 50 or $100 \mathrm{mM} \mathrm{GSH}$ contained an intense Fe peak at ca. $22 \mathrm{~mL}$ (Fig. 5A, trace c) and at ca. $26 \mathrm{~mL}$ (Fig. 5B, trace $\mathrm{c}$ ), simulated in the dashed black lines. Also, trace $\mathrm{c}$ of Fig. 5B exhibited a minor Fe peak at ca. $22 \mathrm{~mL}$ which partially overlapped the dominant sulfur peak centered at $21 \mathrm{~mL}$. We regard both iron peaks (at $22 \mathrm{~mL}$ using $50 \mathrm{mM}$ AA and $26 \mathrm{~mL}$ using $20 \mathrm{mM} \mathrm{AA}$ ) as $\mathrm{Fe}(\mathrm{GSH})$ candidates. This behavior (shifting due to changing the concentration of the coordinating ligand, and development of new peaks

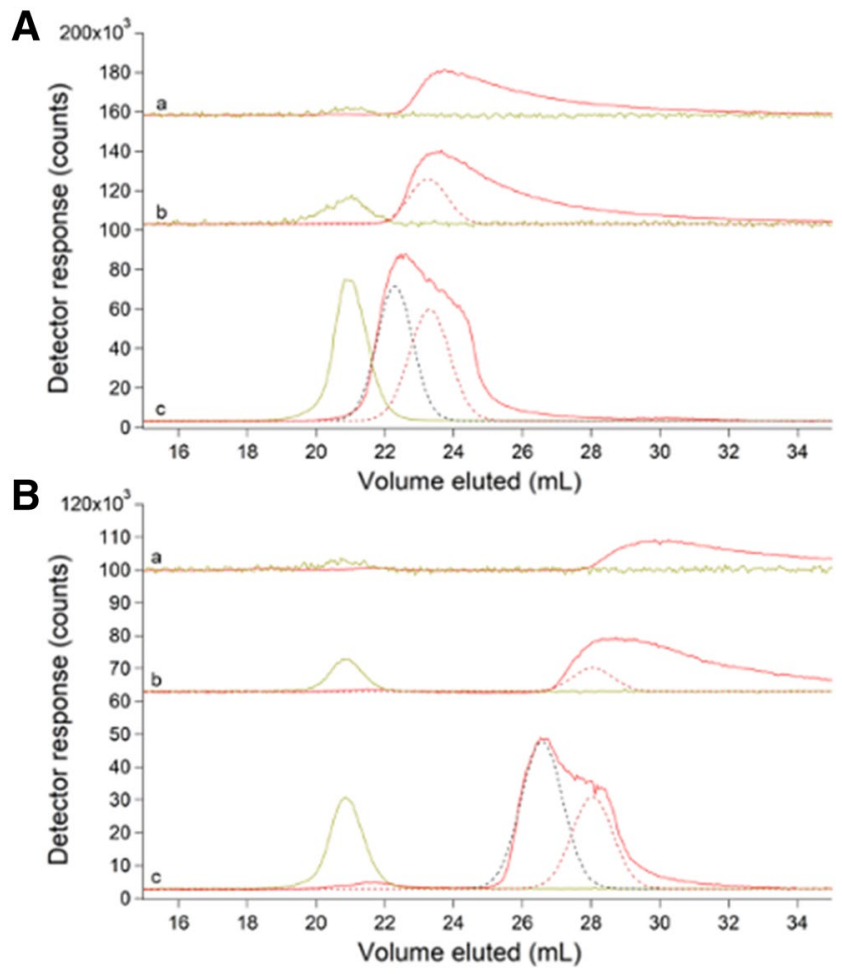


when high concentrations of the ligand are used) indicated weaker binding for $\mathrm{Fe}(\mathrm{GSH})$ than for either $\left[\mathrm{Fe}(\text { phen })_{3}\right]^{2+}$ or $\left[\mathrm{Fe}(\mathrm{BPY})_{3}\right]^{2+}$. Consistent with this assessment, reported stability constant for $\mathrm{Fe}(\mathrm{GSH})$ is $\log \beta=5.1-5.6$ [30].

Despite zinc's strong interaction with the ${ }^{67} \mathrm{Zn}$-loaded column, we assessed its chromatographic properties by mixing $2 \mu \mathrm{M} \mathrm{Zn}$ acetate solutions with either $0.1,1$, or $100 \mathrm{mM}$ GSH (Fig. S3). Each solution was passed down the column (using $50 \mathrm{mM}$ AA mobile phase), and the eluate was monitored for zinc and sulfur. Direct comigration of zinc and sulfur peaks at ca. $21 \mathrm{~mL}$ was only observed when GSH concentration was $100 \mathrm{mM}$ (Fig. S3, trace D); complexation of $\mathrm{Zn}(\mathrm{GSH})$ was confirmed via positive-mode ESI-MS $(\mathrm{m} / \mathrm{z}=370.00,372.00,373.00,374.00)$ for the fraction containing the standard peak. As with the Fe(GSH) standards, when increasing amounts of GSH were mixed with $\mathrm{Zn}$ acetate, a shift in the $\mathrm{Zn}$ trace was observed. This demonstrated weak binding of $\mathrm{Zn}(\mathrm{GSH})$.

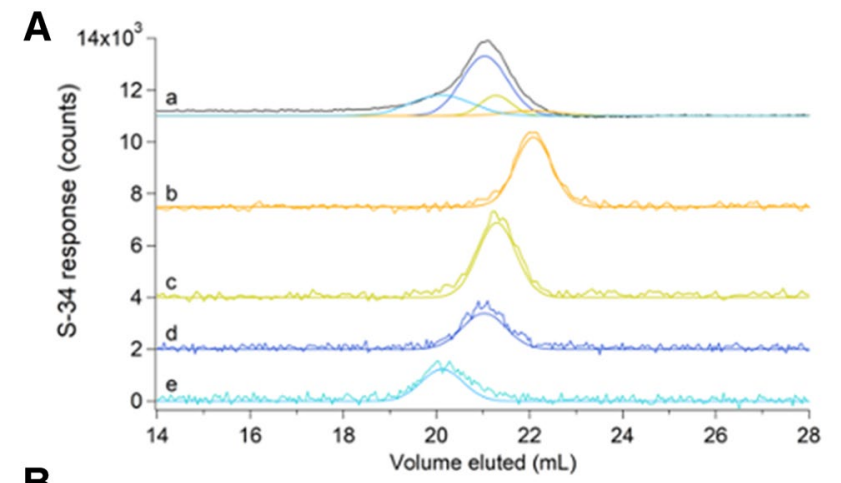

B

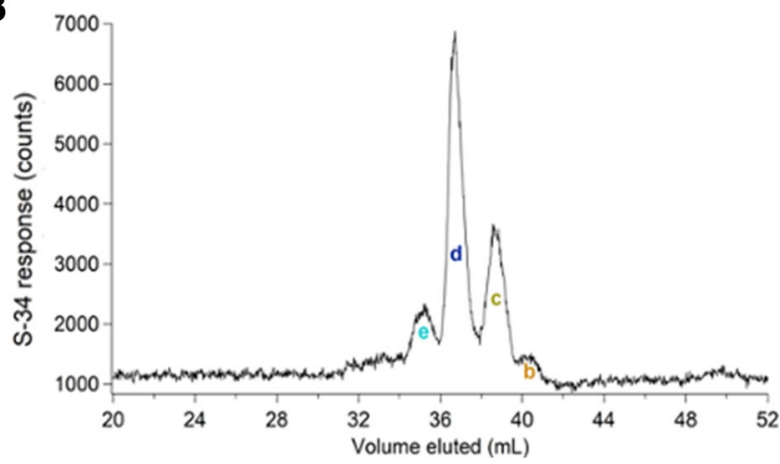

Fig. 6 Sulfur-detected chromatograms of FTS and standards on the single (A) and double (B) column. A: (a), averaged FTS trace (black) and simulations (colored lines coded with standard simulations below). (b), $500 \mu \mathrm{M}$ cysteine; (c), $500 \mu \mathrm{M}$ methionine; (d), $250 \mu \mathrm{M}$ GSH; (e), $250 \mu \mathrm{M}$ GSSG. B: FTS replicate with peaks (b)-(e) correspond to standards in $\mathbf{A}$ that were identified by positive-mode ESIMS

\section{The LMM sulfur pool consisted of GSH, GSSG, methionine and cysteine}

The averaged sulfur-detected trace of cytosolic FTSs exhibited a broad unresolved peak suggesting multiple contributing species (Fig. 6A, trace a). Individual sulfur traces of FTS are given in Fig. S4. Cysteine, methionine, GSH, and GSSG standards migrated in this region (Fig. 6A, traces b-e), suggesting that they might contribute to the observed broad FTS peak. Peaks from each species were simulated (color-coded lines in Fig. 6A, trace a) and combined to recreate the overall experimental trace (black line). To better resolve each contribution, FTS was passed through the double ${ }^{67} \mathrm{Zn}$-loaded column. Sulfur-detected traces exhibited 4 resolved species (Fig. 6B). The ESI-MS spectra of fractions collected when FTS eluted from the double column (Fig. S5) included peaks at $m / z=613.16,308.09,150.06$, and 122.03 Da for LC peaks e, d, c, and b, respectively in Fig. 6B. This confirmed the presence of the GSSG, GSH, methionine, and cysteine as predicted by fitting the unresolved peak obtained with the single column. The intensity of each contributing simulation was converted into absolute concentration using calibrated intensities of standard peaks, and those concentrations were multiplied by the dilution factors involved in isolating FTS. Accordingly, the concentrations of GSH, GSSG, methionine, and cysteine in E. coli cytosol were calculated to be 3000 , 400,800 , and $200 \mu \mathrm{M}$, respectively. The concentration for GSH was similar to previous reports, but lower concentrations have been reported for oxidized glutathione, methionine, and cysteine $(5,150$, and $20-100 \mu \mathrm{M}$, respectively)

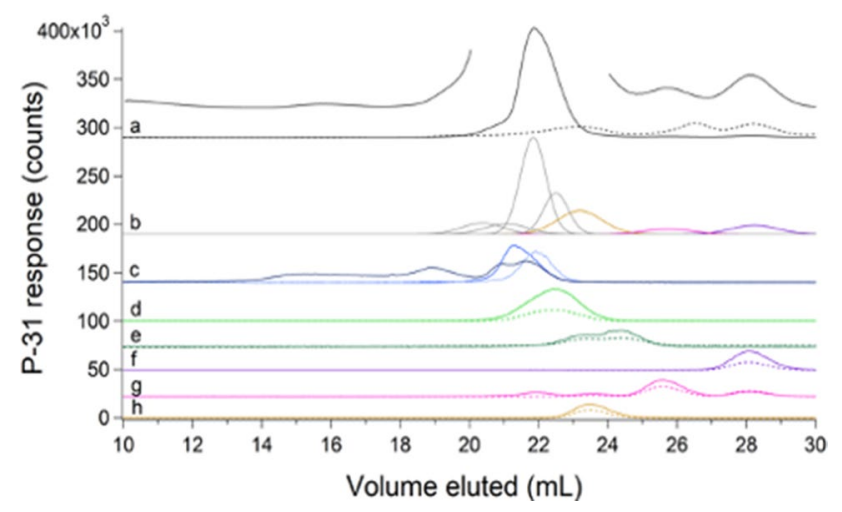

Fig. 7 Phosphorus-detected chromatograms of FTS and standards. a Average traces of FTS detected by ICP-MS (solid black line $\div 10$ ) and at $\mathrm{A}_{260}$ (dashed black line $\times 20$ ). The offset line is the ICP-MS data magnified $\times 2$ excluding the dominating peak. $\mathbf{b}$ Simulations of the FTS color-coded to the standards listed below. c Polyphosphate after ultrafiltration (darker blue); $500 \mu \mathrm{M} \mathrm{NaH} \mathrm{P}_{2} \mathrm{O}_{7} \div 2$ (dark blue), $500 \mu \mathrm{M} \mathrm{Na}_{2} \mathrm{HPO}_{4} \times 5$ (light blue); d $100 \mu \mathrm{M} \mathrm{NADPH} \div 2$ (solid line) and $\mathrm{A}_{260} \times 20$ (dashed line); e $100 \mu \mathrm{M} \mathrm{NADH} \times 5$ (solid line) and $\mathrm{A}_{260} \times 200$ (dashed line); f $100 \mu \mathrm{M} \mathrm{AMP} \times 3$ (solid line) and $\mathrm{A}_{260} \times 20$ (dashed line); g $100 \mu \mathrm{M}$ ADP and $\mathrm{A}_{260} \times 20 ; \mathbf{h} 100 \mu \mathrm{M}$ ATP and $\mathrm{A}_{260} \times 30$ 
[30, 32-34]. No other LMM sulfur species were evident, suggesting that if any were present in cytosol their concentrations must be $<200 \mu \mathrm{M}$.

\section{FTS included many LMM phosphorus-containing metabolites}

The FTS exhibited one intense LMM phosphorus peak (with $V_{e} \approx 22 \mathrm{~mL}$ ) and ca. 6 minor-intensity peaks (Fig. 7, trace a). Individual traces are given in Fig. S6. Solutions of phosphorus standards $\mathrm{Na}_{2} \mathrm{HPO}_{4}, \mathrm{NaH}_{3} \mathrm{P}_{2} \mathrm{O}_{7}, \mathrm{Na}$ (polyphosphate) after ultrafiltration, NADPH, NADH, AMP, ADP, and ATP exhibited peaks (Fig. 7, traces c-h), some of which comigrated with those in the FTS traces (color-coded lines in Fig. 7b). Phosphate and pyrophosphate/polyphosphate traces are presented in Fig. 7c. The peaks from these standards were simulated and the same parameters were used to simulate the peaks in the FTS traces. Negative mode ESI-MS of fractions from FTS eluate established the presence of phosphates $(\mathrm{m} / \mathrm{z}=96.97 ; 194.95 ; 292.92)$, pyrophosphate $(m / z=176.94)$, AMP $(m / z=346.06)$, ADP $(m / z=426.02)$, ATP $(m / z=505.99)$ and NADH $(m / z=664.11)$ (Fig. S7). Inorganic phosphate ions and nucleotides were the main LMM phosphorus species in E. coli cytosol. The total phosphorus concentration in E. coli cytosolic FTS was $140 \pm 40 \mathrm{mM}$. The intracellular inorganic phosphate concentration has been reported to be 1-10 mM [35]. Our concentration was probably higher because the growth media contained a high concentration of phosphate. E. coli cells accumulate excess phosphate ions as polyphosphate in millimolar quantities. Based on our simulations, the ATP and ADP concentrations are 1000 and $200 \mu \mathrm{M}$, respectively, similar to reported concentrations $(1300-2000 \mu \mathrm{M}$ and $450 \mu \mathrm{M}$, respectively) [32, 36]. Reported concentrations of AMP (ca. $70 \mu \mathrm{M}$ ) were dramatically lower than we observed $(1000 \mu \mathrm{M})$. Although ESI-MS analysis established the presence of pyrophosphate, inorganic phosphates, GSSG, GSH, and other potential ligands (citrate, glutamic acid, etc.) in FTSs, no metal-ligand complexes were detected.

\section{Salts in FTSs suppressed ESI-MS signals}

We hypothesized that our inability to detect metal complexes by ESI-MS arose from the presence of salts in the FTS; "salt suppression" is a well-known mass spectrometry phenomenon [37]. To investigate, we obtained ESI-MS spectra of $0.5 \mathrm{mM}$ GSH in water containing $25 \mathrm{mM}$ of each salt present in the growth medium (Fig. S8). The GSH peak was uniformly observed in all samples by ESI-MS, but its intensity in salt solutions relative to that in HPW was strongly diminished. Simple inorganic salts were not well resolved from the GSH peak using the single column (Fig. 8A); however, passing E. coli cytosolic FTS through the double column
A
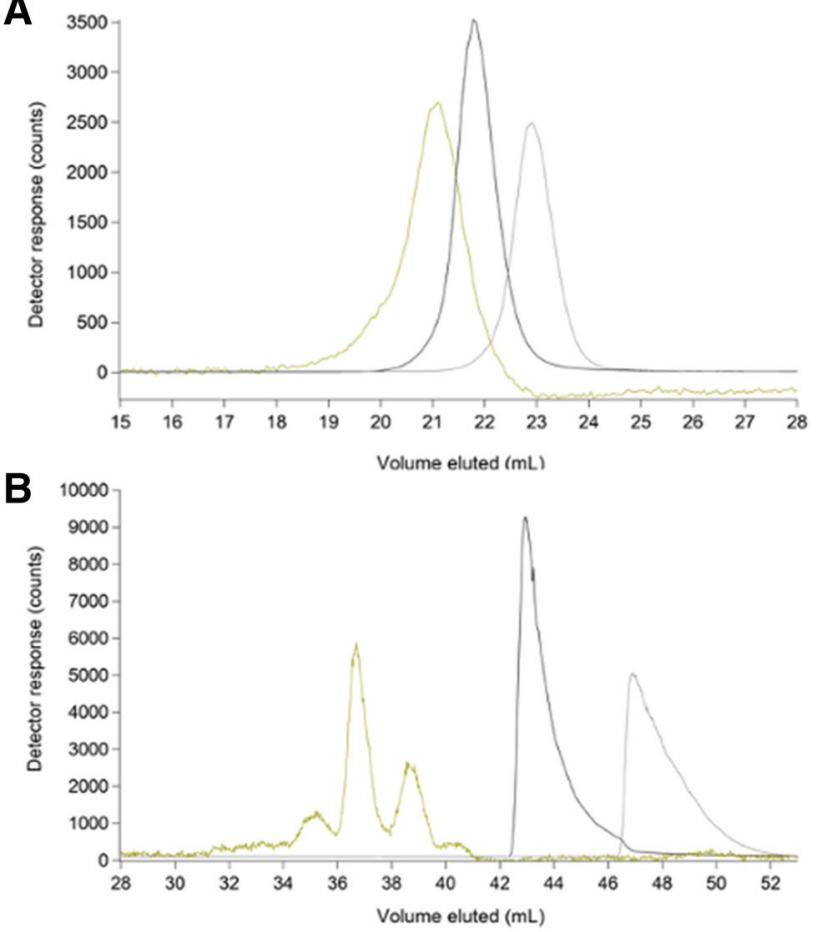

Fig. 8 Chromatograms of FTS on a single (a) and double (b) SEC column, monitoring sulfur (yellow), sodium (black) $\div 5 \times 10^{5}$, and potassium (grey) $\div 10^{4}$

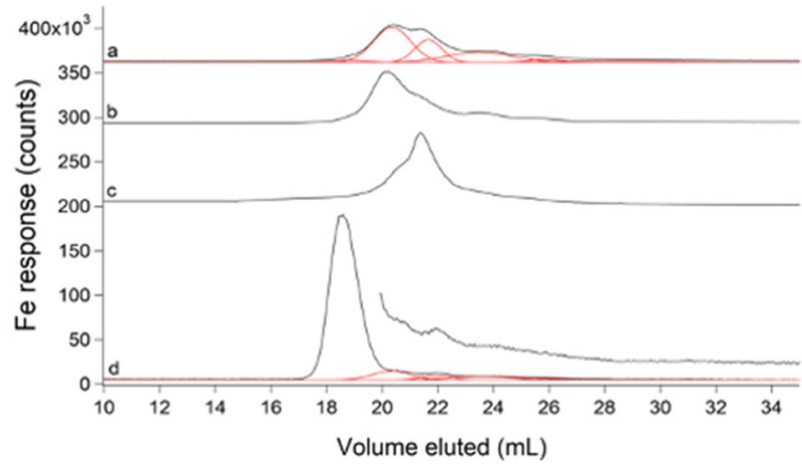

Fig. 9 Iron-detected chromatograms of FTSs. a Average of 8 FTSs (black) and simulations (red); b average of 4 FTSs harvested during mid-exponential growth; c average of 4 FTS from cells supplemented with $100 \mu \mathrm{M} \mathrm{Fe}(\mathrm{III})$ citrate and harvested during mid-exponential growth; d un-supplemented FTS replicate incubated with $500 \mu \mathrm{M}$ BPY and simulations for remaining peaks from $\mathbf{a}$ in red. Offset in $\mathbf{d}$ is the same trace but $\times 3$

resolved these species nicely (Fig. 8B). The improved resolution of the double column was recognized late in our study, and so the single column remained the default. Also, there was a major disadvantage of the double column, namely that processing a sample was $5 \times$ slower than using a single column (200 min vs. $40 \mathrm{~min})$. 


\section{FTS consisted of 2-5 LMM iron species with a collective concentration of $\sim 80 \mu \mathrm{M}$}

Under the growth conditions used, E. coli cells contained $1000 \pm 300 \mu \mathrm{M} \mathrm{Fe}$; isolated cytosol contained $400 \pm 200 \mu \mathrm{M}$ $\mathrm{Fe}$, and the cytosolic FTS contained $80 \pm 20 \mu \mathrm{M}$ Fe. Thus, the labile iron pool in these $E$. coli cells accounted for $8 \%$ of the iron in the cell and $20 \%$ of the iron in the cytosol. When the medium was supplemented with $100 \mu \mathrm{M} \mathrm{Fe}^{\mathrm{III}}$ citrate, the average concentration of iron in the FTS increased to $200 \mu \mathrm{M}$. The range of concentrations determined in 4 independent batches was unusually large $(65 \mu \mathrm{M}$ to $500 \mu \mathrm{M})$ perhaps due to subtle differences in aerobicity during cell growth [21, 38]. It is also possible that some supplemented iron may not have been fully removed despite extensive washing of cells during harvesting.

The average iron-detected trace of FTS revealed five partially overlapping peaks (Fig. 9, trace a). Some individual traces (Fig. S9) exhibited as few as 2 Fe species. The FTS from iron-supplemented cells exhibited similar LC peaks but with different relative intensities (Fig. 9, trace c). There was some variation in iron speciation, possibly dependent on the stage of growth during harvest. Trace b in Fig. 9 was of FTS isolated from cells harvested at mid-exponential phase. The same harvest conditions were used for supplemented growth in Fig. 9c; the shapes of the two curves were closer to each other than to the average trace. BPY was added to one FTS batch; the formation of $\left[\mathrm{Fe}(\mathrm{BPY})_{3}\right]^{2+}$, and the loss of $\sim 70 \%$ intensity relative to the original peaks (Fig. 9 trace $d$ and Fig. 4A, trace b) demonstrated the lability of the original detected LMM iron-containing complexes.

We inadvertently demonstrated the lability of these complexes in another way, namely by treating FTS with acid phosphatase (PPX), which catalyzes the hydrolysis of

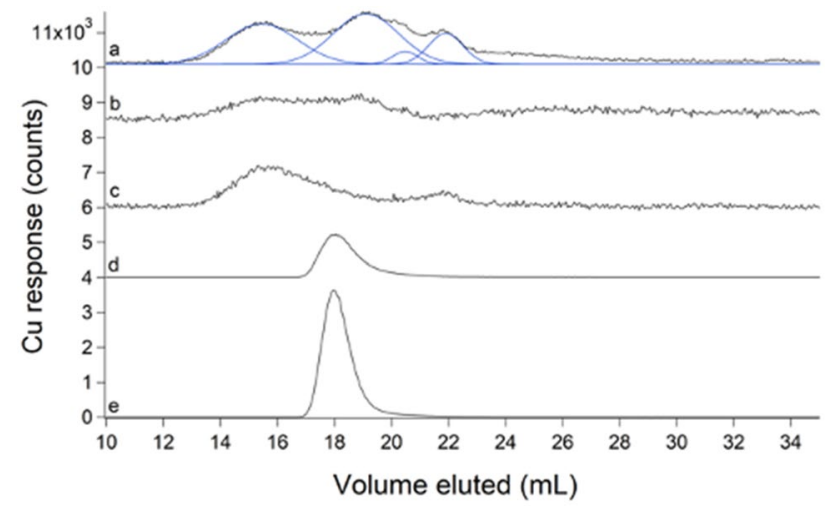

Fig. 10 Copper-detected chromatograms of FTSs (a-d) and standard (e). a Average of 8 FTSs (black) with simulations in blue; b average of 4 FTSs from mid-exponential growth harvest; c FTS from cells supplemented with $1 \mu \mathrm{M}$ of $\mathrm{CuSO}_{4}$ and harvested in mid-exponential phase; d un-supplemented FTS replicate incubated with $50 \mu \mathrm{M}$ $\mathrm{TPEN} \div 100 ;$ e $1 \mu \mathrm{M} \mathrm{CuSO}_{4}+10 \mu \mathrm{M}$ TPEN $\div 200$ polyphosphate chains [39]. The LMM metal species present before treatment were replaced with an increase in metals bound to PPX in the void volume (Fig. S10). This suggested that PPX chelated the LMM metal species in E. coli cytosol. We performed similar experiments previously to evaluate whether LMM metal species in the cytosol of S. cerevisiae were coordinated by polyphosphate ions [22]. At that time, we had difficulty interpreting our results (because metal polyphosphate complexes were not expected to be in the cytosol), but they can now be explained by assuming that PPX chelated metals from LMM metal complexes in the cytosol; PPX-sensitive species in the cytosol of $S$. cerevisiae probably do not coordinate polyphosphate ions.

\section{FTS contained 2-4 LMM copper complexes with a collective concentration of $\sim 10 \mu \mathrm{M}$}

The average copper FTS trace consisted of 4 partially overlapping LMM species with $V_{e}$ between 15 and $22 \mathrm{~mL}$ (Fig. 10, trace a). These species became more intense during late stationary phase. Some individual traces (Fig. S11) exhibited as few as $2 \mathrm{LMM} \mathrm{Cu}$ species. The modest elution volumes and relatively strong peak intensities suggested that these copper species were not aqueous copper ions, as such ions adsorbed strongly to the column (Fig. 2E) in contrast to the apparent undeterred passage of these species. We supplemented the growth medium with $1 \mu \mathrm{M} \mathrm{CuSO}_{4}$ (higher concentrations could not be used because they were toxic). Doing so increased the concentration of the LMM Cu pool from $7 \pm 1$ to $9.3 \pm 0.2 \mu \mathrm{M} \mathrm{Cu}$ (comparison made for midexponential growth phase) and it shifted the relative intensities of the LMM peaks (Fig. 10, trace c). Again, we matched the growth phase of $\mathrm{Cu}$-un-supplemented cells during harvest; the control FTS exhibited trace b in Fig. 10. Copper concentrations in whole cells and cytosol were $8 \pm 2 \mu \mathrm{M}$ and

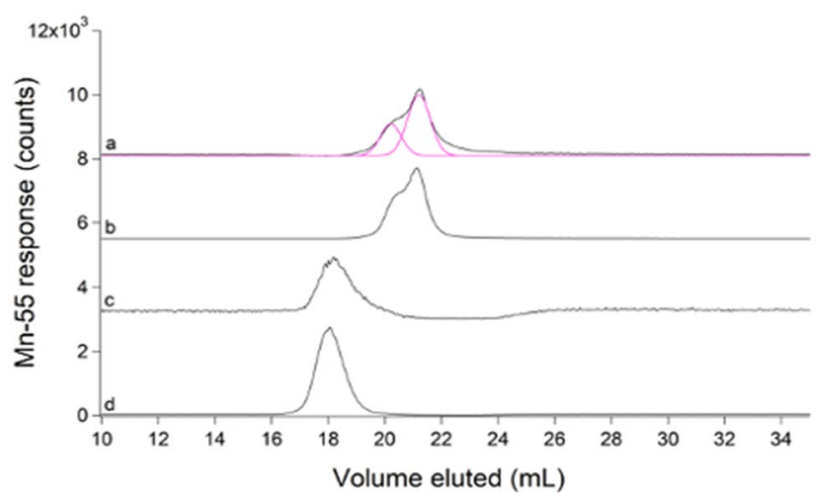

Fig. 11 Manganese-detected chromatograms of FTSs (a-c) and standard (d). a Average of 8 FTSs (black) and simulations (pink); b FTS from cells supplemented with $100 \mu \mathrm{M}$ of $\mathrm{MnCl}_{2} \div 100$; c FTS incubated with $50 \mu \mathrm{M}$ TPEN; d $1 \mu \mathrm{M} \mathrm{MnCl}_{2}+10 \mu \mathrm{M}$ TPEN $\div 20$ 
$6 \pm 2 \mu \mathrm{M}$, respectively. The lability of the LMM copper species was established using the chelator TPEN. LC traces of TPEN-treated FTS exhibited a single peak (Fig. 10, trace d) that comigrated with a $\mathrm{Cu}(\mathrm{TPEN})$ standard (Fig. 10, trace e). We conclude, surprisingly, that E. coli contains a LMM labile copper pool, and that this pool represents the vast majority of the copper (roughly $80 \%$ !) in the cell. Some of this copper may be located in the periplasm since this is the major site of copper metabolism in E. coli [40].

\section{FTS contained LMM manganese and nickel complexes}

Escherichia coli FTS exhibited at least two LMM Mn peaks with $V_{e} \approx 20$ and $21 \mathrm{~mL}$ (Fig. 11, trace a). Individual traces, shown in Fig. S12, were highly reproducible. The peak at $21 \mathrm{~mL}$ was about twice as intense as that at $20 \mathrm{~mL}$. Under our growth conditions, $E$. coli cells and cytosol contained $7 \pm 2 \mu \mathrm{M}$ and $4 \pm 1 \mu \mathrm{M} \mathrm{Mn}$, respectively. The concentration of Mn in FTS was $1.4 \pm 0.7 \mu \mathrm{M}$. Supplementing the growth medium with $100 \mu \mathrm{M} \mathrm{MnCl}_{2}$ in one batch increased the concentration of the labile $\mathrm{Mn}$ pool to $115 \pm 9 \mu \mathrm{M}$-a 70 -fold increase! The Mn trace for this batch was significantly more intense relative to un-supplemented FTSs but peak positions and relative intensities were about the same (Fig. 11, trace b). The lability of the two LMM Mn species was demonstrated using TPEN (Fig. 11c, d).

We did not focus on nickel until late in our study, but a retrospective analysis revealed two at least LMM Ni species in $E$. coli $\mathrm{FTS}$, with $V_{e} \approx 19$ (minor) and 20 (major) $\mathrm{mL}$ (Fig. S13). The concentration of Ni in FTS was $15 \pm 2 \mu \mathrm{M}$. The corresponding sulfur trace comigrated with the $\mathrm{Ni}$ peaks, raising the intriguing possibility of 1-2 LMM Ni-S complex(es).

\section{Discussion}

Escherichia coli and probably all/most prokaryotic and eukaryotic cells contain nonproteinaceous low-molecularmass metal complexes that are used in metal ion trafficking, regulation, and signalling. Although the existence of these complexes has been recognized for decades, the number of species involved, their chemical composition, and their specific roles in cellular physiology remain enigmatic. The fundamental problem is that metal complexes are labile such that their ligands dissociate and reassociate rapidly. The most popular approach to study these "labile metal pools" has been and continues to be using custom-designed fluorescence-based chelator probes. Much progress has been made using chelator probes, but they destroy the complexes of interest during detection, raising doubts that such an approach can ever identify such complexes or establish their cellular roles. We are developing a complementary approach using an LC-ICP-MS system in conjunction with ESI-MS. In this study, we overcame several problems and have set the stage for future advances.

Proper sample preparation is critical for probing labile metal pools; metal chelators and buffers that coordinate metals and/or interfere with ESI-MS analysis should be excluded. EDTA is a common metal chelator that was difficult to eliminate; we did so using a strain of $E$. coli that could be lysed by a simple freeze/thaw cycle. Metals tend to interact with size-exclusion columns which contain basic sites (carboxylate groups) that bind metals. Typically, the ionic strength of the mobile phase is increased to minimize secondary column interactions, but doing so here would have been problematic for ESI-MS and ICP-MS. Thus, we invented a new strategy to combat secondary interactions, namely passing a particular isotope of aqueous zinc ions $\left({ }^{67} \mathrm{Zn}\right)$ through the column which bind tightly to basic sites. Then when detecting zinc-containing eluents by ICP-MS, different zinc isotopes $\left({ }^{66} \mathrm{Zn}\right.$ and $\left.{ }^{68} \mathrm{Zn}\right)$ were monitored. Although the use of a "zinc-loaded" column did not completely inhibit all interactions and the column required periodic reloading, it minimized these problems and afforded greater reproducibility.

Using a Zn-loaded column, the chromatographic behavior of metal complexes was found to depend on the binding strength of the complex. Tight-binding complexes like $\left[\mathrm{Fe}(\mathrm{phen})_{3}\right]^{2+}$ and $\left[\mathrm{Fe}(\mathrm{BPY})_{3}\right]^{2+}$ passed through the column intact whereas intermediate-binding complexes like $\mathrm{Fe}(\mathrm{ATP})$ and $\mathrm{Fe}(\mathrm{GSH})$ exhibited complex behavior in which the elution profile of the metal varied with the concentration of the coordinating ligand. Weak-binding metal complexes like hexaquairon eluted slowly from the column and exhibited excessive broadening/tailing due to extensive column interactions.

We also assessed the importance of the mobile phase in chromatographic behavior; this was especially important for weak-binding metal complexes that interact strongly with the column. Mobile phase buffers with lower ionic strength promoted metal complexes to remain intact as they pass through the column but also promoted greater column interactions.

Finally, we identified salt suppression as a major problem in identifying labile metal pools by ESI-MS in aqueous cellular solutions since such solutions contain high concentrations of salts. We found that using two SEC columns linked in series was an effective, albeit time-intensive, strategy for separating LMM nonproteinaceous metal complexes from salt-containing solutions.

With these lessons learned, we assessed the labile iron, zinc, copper, manganese and nickel pools in E. coli cytosol as well as LMM pools of sulfur and phosphorus. As expected, the major LMM sulfur species was GSH, followed by GSSG, methionine, and cysteine. The major LMM 
phosphorus species in the cytosol were inorganic phosphate ions and LMM polyphosphates followed by ATP, ADP, $\mathrm{NADH}$, etc. Due to the limited resolving capabilities of the single SEC column, the concentration of inorganic phosphate and LMM polyphosphates could not be determined; however, the calculated concentrations of later-eluting $\mathrm{P}$ species (ATP and ADP) were similar to those reported. The increased concentration of AMP observed relative to previous reports likely resulted from the DNA hydrolysis step in our cytosol isolation protocol which generates nucleotide monophosphates. While metal ions are capable of binding monophosphate groups of nucleotide monophosphates, no LMM metal species present in E. coli cytosol comigrated with AMP. Thus, the high concentration of nucleotide monophosphates should not have influenced the LMM metal pools.

Outten and O'Halloran concluded that WT E. coli cells are devoid of "free" (i.e. aqueous) $\mathrm{Zn}$ ions based on experiments in which Zur and ZntR transcription factors were titrated with aqueous zinc [41]. Zn-bound Zur suppresses $\mathrm{Zn}$ import whereas Zn-bound ZntR stimulates Zn export. An aqueous $\mathrm{Zn}$ concentration of $10^{-15} \mathrm{M}$ minimized both activities suggesting that $E$. coli cells operate under homeostatically-regulated conditions centered around this concentration. However, this concentration corresponds to less than one atom of aqueous $\mathrm{Zn}$ per cell. Using our system, aqueous $\mathrm{Zn}$ ions interacted strongly with the column, and they eluted as broad tailing features at large volumes. In contrast, labile LMM Zn complexes with stronger ligands eluted earlier and as sharp peaks, indicating less interaction with the column. The LMM Zn peaks that we detected are in the latter category. We conclude that $E$. coli cytosol contains $\mu \mathrm{M}$ concentrations of labile LMM nonproteinaceous $\mathrm{Zn}$ complexes but not aqueous or "free" $\mathrm{Zn}$ ions. This supports Outten and O'Halloran's conclusion that there is no "free" $\mathrm{Zn}$ in the cell [41], but clarifies that there is a significant labile zinc pool nevertheless. The LMM labile $\mathrm{Zn}$ species could potentially be involved in $\mathrm{Zn}$ trafficking and regulation, and/ or perhaps metallating the $\mathrm{Zn}$ proteome in E. coli. The situation is different when $E$. coli cells are grown in media that is supplemented with $\mathrm{Zn}$. In this case, the cytosol contains high concentrations $\left(10^{-5} \mathrm{M}\right)$ of either aqueous $\mathrm{Zn}$ ions or weaker binding $\mathrm{Zn}$ complexes that dissociate as they migrate down the column. Perhaps under Zn-stressed conditions, a secondary ligand of intermediate-binding strength sequesters excess $\mathrm{Zn}$ ions in the cytosol. Based on the range of $\mathrm{Zn}$ concentrations observed upon media supplementation, cells containing high zinc may have been harvested in a transient state in which excess $\mathrm{Zn}$ was being actively trafficked and subsequently exported.

Bacillus subtilis and other Gram-positive bacteria use bacillithiol (BSH), a sugar-based LMM molecule with cysteine and malic acid groups attached, as a $\mathrm{Zn}$ buffer. $\mathrm{Zn}$ likely coordinates to the thiol, carboxylates, and/or amide functional groups. Helmann et al. [42] have shown that the $\mathrm{Zn}(\mathrm{BSH})$ complex is strong-binding and present in the cell at sufficiently high $(5 \mathrm{mM})$ concentrations such that the concentration of aqueous $\mathrm{Zn}$ ions should be exceedingly low. They and others have suggested that GSH plays the same buffering role in E. coli and in other cells that contain GSH. Besides GSH, other potential ligands for the labile zinc pool include ATP, citrate, and amino acids [6, 43], all of which have been detected by ESI-MS of fractions from FTS eluate.

Hider and Kong have presented thermodynamic-based arguments that $\mathrm{Fe}(\mathrm{GSH})$ is the dominant LMM labile $\mathrm{Fe}$ complex in the cytosol [30, 31]. They simulated iron complex formation in the cytosol using known affinity constants, concentrations, $\mathrm{pH}$, and redox properties. In support of this, we found that solutions of iron mixed with GSH at high concentrations afforded an LC peak that eluted ca. $22 \mathrm{~mL}$ suggesting complex formation. However, we were unable to demonstrate that any of the detected labile iron species in FTS was $\mathrm{Fe}(\mathrm{GSH})$, perhaps due to salt suppression in our samples.

Previous studies from our lab reported two LMM iron species in E. coli with similar apparent masses as observed here [21]. Mössbauer spectra of the LMM iron species in E. coli have parameters typical of complexes with 5-6 O/N ligands-and no sulfur [21]. However, previous batches used EDTA during cytosol isolation, and we are concerned that the Fe(EDTA) complex had formed and displaced the endogenous iron complexes. Further studies are required to determine this. The concentration of LMM iron in E. coli was previously reported at $\sim 200 \mu \mathrm{M}, 2-3$ times higher than observed here. However, growth conditions strongly affect the LIP concentration; for example, under aerobic conditions, the LIP concentration was only $\sim 50 \mu \mathrm{M}$. Martin et al. determined a free intracellular iron concentration of $100 \mu \mathrm{M}$ [44]. Daly et al. reported ultrafiltrate iron concentrations of just $1.2 \mu \mathrm{M}$ [45].

Like $\mathrm{Zn}$, copper trafficking in both eukaryotic and prokaryotic cells does not involve aqueous copper ions [46, 47]. Rather, copper is thought to be trafficked using copper-binding protein chaperones. Thus, the presence of nonproteinaceous LMM copper species in our FTSs was unexpected though we have recently detected similar LMM copper species in the cytosol of S. cerevisiae [22]. We have not chemically identified these copper species, but our results indicate that they are not simple aqueous copper ions; such ions adsorbed strongly to the column whereas the detected species eluted from the column at low $V_{e}$ and sharp Gaussian lineshapes. Even more surprising is that the detected LMM copper species represent the majority of copper in the cell.

The labile Mn species that we detected showed little interaction with the column, suggesting strong-binding ligands, but they also migrated in the same region as aqueous $\mathrm{Mn}$ 
ions. Unstressed E. coli cells do not appear to use Mn, but under stressed conditions, Mn replaces iron in superoxide dismutase and ribonucleotide reductase [44]. We suggest that the detected species metallates those enzymes. WT $E$. coli grown in LB medium reportedly contain ca. $5 \mu \mathrm{M}$ Mn (similar to what we observed), most of which was associated with MnSOD [44]. Similar to our results, Martin et al. also observed a strong increase of $\mathrm{Mn}$ concentration in $E$. coli (to $35 \mu \mathrm{M})$ when media was supplemented with $\mathrm{Mn}$, and they observed whole-cell EPR indicating that this was in the $\mathrm{Mn}^{\mathrm{II}}$ oxidation state. Daly et al. reported $13 \mu \mathrm{M}$ manganese in $E$. coli cells and $0.3 \mu \mathrm{M}$ Mn in FTSs [45]. Sharma et al. 2013 used electron spin-echo EPR and ENDOR spectroscopy to characterize the LMM Mn in E. coli [48]. They concluded that $\mathrm{LMM} \mathrm{Mn}{ }^{\mathrm{II}}$ ions were coordinated by orthophosphate or other phosphorus-containing ligands, some waters, but few, if any, nitrogen-containing ligands. While comigration between Mn and P traces was observed in our cytosolic FTS, further investigation is needed to determine if the LMM Mn pool of $E$. coli is ligated by phosphorus-containing ligands.

Under anaerobic conditions, E. coli expresses the nickel permease system NikBCDE that imports $\mathrm{Ni}$ ions which are then trafficked to Ni-containing NiFe hydrogenases $[49,50]$. Trafficking involves a number of metallochaperone proteins as well as a $\mathrm{Ni}(\mathrm{L}-\mathrm{His})_{2}$ complex [51]. However, since our cells were grown aerobically, the $\mathrm{Ni}$ species that we detected may not be associated with these processes. Under aerobic conditions, E. coli needs nickel for glyoxalase, with nickel imported (inefficiently) by magnesium transporters [52, 53]. Further studies are required to establish the composition and cellular function of the detected nickel species.

In summary, the identification and characterization of labile metal pools in cells are extremely important in understanding metal ion trafficking, signalling, and regulation; however, this task is challenging due to the inherent lability of these complexes. In this study, we report major advances in overcoming problems and attaining this objective using LC-ICP-MS and ESI-MS. These advances position us closer than ever to identifying the sought-after endogenous LMM metal complexes that constitute labile metal pools in E. coli and other biological systems.

Major results and conclusions of this study:

- A strain of E. coli was employed which allowed lysates to be prepared without using EDTA.

- Pre-loading a size-exclusion chromatography column with ${ }^{67} \mathrm{Zn}$ occupied sites on the column matrix that would have otherwise reacted with metal ions that migrated through the column. Then when zinc-containing samples were subsequently applied to the "zinc-loaded" column, ${ }^{66} \mathrm{Zn}$ was detected and ${ }^{67} \mathrm{Zn}$, which slowly leached from the column, was ignored.
- Even using a zinc-loaded column, aqueous (or "free") metal ions interacted with it, slowing their elution.

- A "ghost column" consisting of PEEK tubing that replaced the actual column was used to evaluate the proportion of metal ions in a sample that adhered to the column. The degree of column interaction varied approximately with the Irving-Williams series: $\mathrm{Mn}$ (least) $<\mathrm{Fe}<\mathrm{Ni}<\mathrm{Zn}<\mathrm{Cu}$ (most)

- The mobile-phase buffer impacted chromatographic behavior; lower ionic strength promoted metal complexes to remain intact as they pass through the column but also promoted greater column interactions.

- The chromatographic behavior of iron and zinc standards reflected the $\mathrm{M}-\mathrm{L}$ binding strength of the complex; thermodynamically stable complexes (e.g. bound to 1,10-phenanthroline and 2,2'-bipyridyl) held together as they migrated down the column whereas less stable complexes [e.g. $\mathrm{Fe}^{\mathrm{II}}(\mathrm{ATP})$ and $\left.\mathrm{Fe}^{\mathrm{II}}(\mathrm{GSH})\right]$ showed evidence of some dissociation (shifting elution volumes with changing ligand:metal ratios and mobile phase buffer composition).

- With low-molecular-mass standards (less than $1000 \mathrm{Da}$ ), elution volumes did not follow calibration curves, such that all masses obtained using such curves should be considered apparent.

- The $\mathrm{Zn}(\mathrm{GSH})$ complex migrated in-tact through the column, but only at high GSH concentrations. This complex was detected by ESI-MS.

- The LMM sulfur pool in cytosol consisted of GSH, GSSG, methionine and cysteine, as confirmed by ESIMS. Approximate cytosolic concentrations were 3000, 400,800 , and $200 \mu \mathrm{M}$, respectively.

- The LMM phosphorus pool in cytosol consisted of 1 intense LC peak and ca. 6 minor peaks. ESI-MS established the presence of phosphates, pyrophosphate, AMP, ADP, ATP and NADH. The dominant LC peak probably arose from phosphate ions and nucleotides. Estimated ATP, ADP, and AMP concentrations were 1000,200 , and $1000 \mu \mathrm{M}$, respectively.

- No endogenous Fe, $\mathrm{Zn}, \mathrm{Cu}$, or Mn complexes in cytosol were detected by ESI-MS, probably due to salt suppression and low concentrations. Salt suppression was a major problem because cytosol and other cell compartments contain high concentrations of salts. Using a longer column diminished this problem but also diluted samples.

- Cytosolic flow-through-solution from E. coli cells contained 2-5 labile LMM zinc complexes with a collective concentration of $\sim 13 \mu \mathrm{M}$. Supplementing the growth medium with $100 \mu \mathrm{M} \mathrm{Zn}$ acetate led to a $\mathrm{Zn}$ pool concentration of $\sim 200 \mu \mathrm{M}$.

- The E. coli cytosol consists of 2-5 LMM iron species with a collective concentration of $\sim 80 \mu \mathrm{M}$. For the 
growth conditions used, this represented $8 \%$ of the iron in the cell and $20 \%$ of the iron in the cytosol. When cells were grown on high iron, the concentration of iron in the FTS increased to $\sim 200 \mu \mathrm{M}$.

- After the FTS was treated with BPY, iron LC peaks declined $\sim 70 \%$ indicating that the detected peaks were labile as commonly defined.

- FTS contained 2-4 LMM copper complexes with a collective concentration of $\sim 10 \mu \mathrm{M}$. These complexes are not aqueous (or "free") copper; such ions adhere tightly to the column. Increasing the copper concentration in the growth medium had little effect on the copper concentration in the FTS, but the relative intensities of the peaks changed. Surprisingly, E. coli contains a LMM labile copper pool that represents the vast majority $(\sim 80 \%)$ of the copper in the cell.

- FTS contained 2 LMM manganese species with a collective concentration of $\sim 1.4 \mu \mathrm{M}$. These species represented $20 \%$ of the manganese in the cell. Supplementing $\mathrm{Mn}$ in the growth increased the Mn concentration in the FTS hugely.

- FTS contained 2 LMM Ni species with a collective concentration of $\sim 15 \mu \mathrm{M}$. These peaks comigrated with sulfur suggesting LMM Ni-S complex(es) in E. coli.

Supplementary Information The online version contains supplementary material available at https://doi.org/10.1007/s00775-021-01864-w.

Acknowledgements We thank Ryland Young (TAMU) for providing background strain MG1655 and plasmid pZa31mycR and Yohannes Rezenom of the Chemistry Mass Spectrometry Laboratory (TAMU) for ESI-MS data collection.

Author contributions HNB performed the experiments, analyzed the data, and prepared figures and tables; PAL offered advice, helped analyze the data, and wrote much of the paper. Both authors edited the paper and agreed to its submission.

Funding This work was supported by the National Institutes of Health (GM127021), the National Science Foundation (MCB-1817389), and the Robert A. Welch Foundation (A1170). The content of this article is solely the responsibility of the authors and does not necessarily represent the official views of the NIH, NSF, or the Welch Foundation.

\section{Declarations}

Conflict of interest There are no conflicts or competing interests to declare.

Availability of data and material Chromatography data are available upon request.

Open Access This article is licensed under a Creative Commons Attribution 4.0 International License, which permits use, sharing, adaptation, distribution and reproduction in any medium or format, as long as you give appropriate credit to the original author(s) and the source, provide a link to the Creative Commons licence, and indicate if changes were made. The images or other third party material in this article are included in the article's Creative Commons licence, unless indicated otherwise in a credit line to the material. If material is not included in the article's Creative Commons licence and your intended use is not permitted by statutory regulation or exceeds the permitted use, you will need to obtain permission directly from the copyright holder. To view a copy of this licence, visit http://creativecommons.org/licenses/by/4.0/.

\section{References}

1. Finney LA, O'Halloran TV (2003) Transition metal speciation in the cell; insights from the chemistry of metal ion receptors. Science 300:931-936

2. Imlay JA (2003) Pathways of oxidative damage. Ann Rev Microbiol 57:395-418

3. Macomber L, Imlay JA (2009) The iron-sulfur clusters of dehydratases are primary intracellular targets of copper toxicity. Proc Natl Acad Sci USA 106:8344-8349

4. Imlay JA (2014) The mismetallation of enzymes during oxidative stress. J Biol Chem 289:28121-28128

5. Gu M, Imlay JA (2013) Superoxide poisons mononuclear iron enzymes by causing mismetallation. Mol Microbiol 89:123-134

6. Krężel A, Maret W (2016) The biological inorganic chemistry of zinc ions. Arch Biochem Biophys 611:3-19

7. Lindahl PA, Moore MJ (2016) Labile low-molecular-mass metal complexes in mitochondria: trials and tribulations of a burgeoning field. Biochemistry 55:4140-4153

8. O'Halloran TV, Culotta VC (2000) Metallochaperones, an intracellular shuttle service for metal ions. J Biol Chem 275:25057-25060

9. Ma Z, Jacobsen FE, Giedroc DP (2009) Coordination chemistry of bacterial metal transport and sensing. Chem Rev 109:4644-4681

10. Wilson S, Bird AJ (2016) Zinc sensing and regulation in yeast model systems. Arch Biochem Biophys 611:30-36

11. Jacobs A (1977) Low-molecular weight intracellular iron transport compounds. Blood 50:433-439

12. Williams RJP (1982) Free manganese(II) and iron(II) cations can act as intracellular cell controls. FEBS Lett 140:3-10

13. Crichton (RR), (1984) Iron uptake and utilization by mammalian cells II. Intracellular iron utilization. Trends Biochem Sci 9:283-286

14. Lisher JP, Giedroc DP (2013) Manganese acquisition and homeostasis at the host-pathogen interface. Front Cell Infect Microbiol 3:91. https://doi.org/10.3389/fcimb.2013.00091

15. Braymer JJ, Giedroc DP (2014) Recent developments in copper and zinc homeostasis in bacterial pathogens. Curr Opin Chem Biol 19:59-66

16. Petrat F, de Groot H, Sustmann R, Rauen U (2002) The chelatable iron pool in living cells: a methodically defined quantity. Biol Chem 383:489-502

17. Petrat F, Rauen U, de Groot H (1999) Determination of the chelatable iron pool of isolated rat hepatocytes by digital fluorescence microscopy using the fluorescent probe, phen green SK. Hepatology 29:1171-1179

18. Zastrow ML, Huang Z, Lippard SJ (2020) HaloTag-Based Hybrid Targetable and Ratiometric Sensors for Intracellular Zinc. ACS Chem Biol 15:396-406

19. Chung CYS, Posimo JM, Lee S, Tsang T, Davis JM, Brady DC, Chang CJ (2019) Activity-based ratiometric FRET probe reveals oncogene-driven changes in labile copper pools induced by altered glutathione metabolism. Proc Natl Acad Sci USA 116:18285-18294 
20. Carter KP, Young AM, Palmer AE (2014) Fluorescent sensors for measuring metal ions in living systems. Chem Rev 114:4564-4601

21. Wofford JD, Bolaji N, Dziuba N, Outten FW, Lindahl PA (2019) Evidence that a respiratory shield in Escherichia coli protects a low molecular mass $\mathrm{Fe}^{\mathrm{II}}$ pool from $\mathrm{O}_{2}$-dependent oxidation. $\mathrm{J}$ Biol Chem 294:50-62

22. Nguyen TQ, Kim JE, Brawley HN, Lindahl PA (2020) Chromatographic detection of low-molecular-mass metal complexes in the cytosol of Saccharomyces cerevisiae. Metallomics 12:1094-1105

23. Dziuba N, Hardy J, Lindahl PA (2019) Low-molecular-mass iron complexes in blood plasma of iron-deficient pigs do not originate directly from nutrient iron. Metallomics 11:1900-1911

24. McCormick SP, Moore MJ, Lindahl PA (2015) Detection of labile low-molecular-mass transition metal complexes in mitochondria. Biochemistry 54:3442-3453

25. Cahill J, Young R (2019) Phage lysis: multiple genes for multiple barriers. Adv Virus Res 103:33-70

26. Hellberg U, Ivarsson JP, Johansson BL (1996) Characteristics of Superdex ${ }^{\circledR}$ prep grade media for gel filtration chromatography of proteins and peptides. Process Biochem 31:163-172

27. Irving H, Williams RJP (1948) Order of stability of metal complexes. Nature 162:746-747

28. Weaver J, Pollack S (1989) Low-Mr iron isolated from guinea pig reticulocytes as AMP-Fe and ATP-Fe complexes. Biochem J 261:787-792

29. Smith RM, Martell AE (1990) Critical stability constants, vol 2. Plenum Publishing Corp, New York

30. Hider RC, Kong XL (2011) Glutathione: a key component of the cytoplasmic labile iron pool. Biometals 24:1179-1187

31. Hider RC, Kong XL (2013) Iron speciation in the cytosol: an overview. Dalton Trans 42:3220-3229

32. Bennett BD, Kimball EH, Gao M, Osterhout R, Van Dien SJ, Rabinowitz JD (2009) Absolute metabolite concentrations and implied enzyme active site occupancy in Escherichia coli. Nature Chem Biol 5:593-599

33. Helbig K, Bleuel C, Krauss GJ, Nies DH (2008) Glutathione and transition-metal homeostasis in Escherichia Coli. J Bacteriol 190:5431-5438

34. Smirnova GV, Tyulenev AV, Bezmaternyk KV, Muzyka NG, Ushakov VY, Oktyabrsky ON (2019) Cysteine homeostasis under inhibition of protein synthesis in Escherichia coli cells. Amino Acids 51:1577-1592

35. McCleary WR (2017) Molecular mechanisms of phosphate homeostasis in Escherichia coli. Recent Adv Physiol Pathog Biotechnol Appl. https://doi.org/10.5772/67283

36. Zbornickova E, Knejzlika R, Hauryliuk V, Krasny L, Rejman D (2019) Analysis of nucleotide pools in bacteria using HPLC-MS in HILIC mode. Talanta 205:120161. https://doi.org/10.1016/j. talanta.2019.120161

37. Piwowar AM, Lockyer NP, Vickerman JC (2009) Salt effects on ion formation in desorption mass spectrometry: an investigation into the role of alkali chlorides on peak suppression in Time-of-Flight-Secondary Ion Mass Spectrometry. Anal Chem 81:1040-1048

38. Beauchene NA, Mettert EL, Moore LJ, Keles S, Willey ER, Kiley PJ (2017) $\mathrm{O}_{2}$ availability impacts iron homeostasis in Escherichia coli. Proc Natl Acad Sci USA 114:12261-12266
39. Akiyama M, Crooke E, Kornberg A (1993) An exopolyphosphatase of Escherichia coli. the enzyme and its ppx gene in a polyphosphate operon. J Biol Chem 268:633-639

40. Rensing C, Grass G (2003) Escherichia coli mechanisms of copper homeostasis in a changing environment. FEMS Microbiol Rev 27:197-213

41. Outten CE, O'Halloran TV (2001) Femtomolar sensitivity of metalloregulatory proteins controlling zinc homeostasis. Science 292:2488-2492

42. Ma P, Chandrangsu TC, Helmann A, Romsang A, Gaballa A, Helmann JD (2014) Bacillithiol is a major buffer of the labile zinc pool in Bacillus subtilis. Mol Microbiol 94:756-770

43. Glover CN, Bury NR, Hogstrand C (2003) Zinc uptake across the apical membrane of freshwater rainbow trout intestine is mediated by high affinity, low affinity, and histidine-facilitated pathways. Biochim Biophys ACTA 1614:211-219

44. Martin JE, Waters LS, Storz G, Imlay JA (2015) The Escherichia coli Small protein MntS and exporter MntP optimize the intracellular concentration of manganese. PLoS Genet 11:e1004977. https://doi.org/10.1371/journal.pgen.1004977

45. Daly MJ, Gaidamakova EK, Matrosova VY, Kiang JG, Fukumoto R, Lee DY, Wehr NB, Viteri GA, Berlett BS, Levine RL (2010) Small-molecule antioxidant proteome-shields in Deinococcus radiodurans. PLoS ONE 5:e12570. https://doi.org/10.1371/journ al.pone. 0012570

46. Rae TD, Schmidt PJ, Pufahl RA, Culotta VC, O'Halloran TV (1999) Undetectable intracellular free copper: The requirement of a copper chaperone for superoxide dismutase. Science 284:805-808

47. Changela A, Chen K, Xue Y, Holschen J, Outten CE, O'Halloran TV, Mondragón A (2003) Molecular basis of metal-ion selectivity and zeptomolar sensitivity by CueR. Science 301:1383-1387

48. Sharma A, Gaidamakova EK, Matrosova VY, Bennett B, Daly MJ, Hoffman BM (2013) Responses of $\mathrm{Mn}^{2+}$ speciation in Deinoccoccus radiodurans and Escherichia coli to $\gamma$-radiation by advanced paramagnetic resonance methods. Proc Natl Acad Sci USA 110:5945-5950

49. Higgins KA, Carr CE, Maroney MJ (2012) Specific metal recognition in nickel trafficking. Biochemistry 51:7816-7832

50. Miki K, Atomi H, Watanabe S (2020) Structural Insight into [NiFe] hydrogenase maturation by transient complexes between Hyp Proteins. Acc Chem Res 53:875-886

51. Chivers PT, Benanti EL, Heil-Chapdelaine V, Iwig JS, Rowe JL (2012) Identification of Ni-(L-His)(2) as a substrate for NikABCDE-dependent nickel uptake in Escherichia coli. Metallomics 4:1043-1050

52. Boer JL, Mulrooney SB, Hausinger RP (2014) Nickel-dependent metalloenzymes. Arch Biochem Biophys 544:142-152

53. Moncrief MB, Maguire ME (1999) Magnesium transport in prokaryotes. J Biol Inorg Chem 4:523-527

Publisher's Note Springer Nature remains neutral with regard to jurisdictional claims in published maps and institutional affiliations. 